\section{Measuring Systematic Monetary Policy}

\author{
Kevin D. Hoover and Oscar Jordá
}

T he financial press hangs on the words of every Governor of the Federal Reserve Board, every President of a Federal Reserve Bank, and most of all, of course, on the words of Chairman Alan Greenspan. In his testimony to the Senate Banking Committee on July 20, 2000, Greenspan said:

Most recently we have needed to raise rates to relatively high levels in real terms in response to the side effects of accelerating growth and related demand-supply imbalances. Variations in the stance of policyor keeping it the same-in response to evolving forces are made in the framework of an unchanging objective-to foster as best we can those financial conditions most likely to promote sustained economic expansion at the highest rate possible ... Irrespective of the complexities of economic change, our primary goal is to find those policies that best contribute to a noninflationary environment and hence to growth. The Federal Reserve, I trust, will always remain vigilant in pursuit of that goal.

Chairman Greenspan is well known for his inscrutability; yet the message here is exactly the one that the financial markets read into Federal Reserve policy: while ultimately it may aim to control inflation, it does so through contingent responses to inflation and real developments, and it expects its policy actions to affect the real economy systematically. The manner in which the Federal Reserve determines these contingent responses is central in the analysis of optimal policyreactions function - provided, of course, that the Fed is right and that systematic monetary policy does have economically significant effects on the real economy.

Kevin D. Hoover and Oscar Jordá are professors of economics at the University of California, Davis. The authors thank Simon Gilchrist, Charles Goodhart, Clinton Greene, Alan Melzter, Valerie Ramey, Kevin Salyer, Daniel Thornton, Kenneth West, and the participants in the Federal Reserve Bank of St. Louis's Conference on Monetary Policy in Theory and Practice, October 2000, for helpful comments.
Starting in the early 1970s, new classical economists led by Robert Lucas began to question whether systematic monetary policy in fact had the required real effects. Over time, many macroeconomists have come to believe that, because of substantial frictions (e.g., price stickiness and limited participation in financial markets), systematic monetary policy does matter. Recent empirical analysis of monetary policy has typically used the econometric framework of vector autoregressions (VARs). Motivated in large measure by Lucas's argument that the coefficients of estimated macroeconomic relationships should not be invariant to changes in monetary-policy regime (the "Lucas critique"), practitioners have focused on unanticipated and unsystematic policy shocks. These shocks account for little of the variability of the instruments of monetary policy and, naturally, are of less interest to markets or politicians than is systematic policy. Yet the way in which VARs are interpreted implicitly assumes that Lucas's original argumentthat systematic monetary policy is ineffective-is correct. There is a logical disconnection between the usual way in which VARs are interpreted and the belief that systematic monetary policy matters.

The aim of this paper is to analyze systematic monetary policy in a VAR framework in a way that is logically consistent. The key insight-originally by John Cochrane (1998) - is that the effect of systematic monetary policy depends on the balance of economic actors between those who behave as ideal new classical agents (frictionless competitors with rational expectations) and those who follow rules of thumb or face other frictions. Our own innovation is to suggest a method of using regime changes (the Lucas critique) to identify that balance empirically. Our purpose is both critical (we try to understand some of the recent literature in a common framework) and positive (we present an empirical assessment of U.S. monetary policy).

\section{MONETARY POLICY AFTER LUCAS AND SIMS}

Before the 1970s quantitative monetary-policy analysis had two important features. Orthodox monetary policy was typically viewed in a targetand-instruments framework in which the monetary authority sought to achieve a goal for inflation, gross domestic product (GDP), or unemployment using money or some more directly controllable monetary instrument as the means. Monetarists 
and Keynesians debated the relative merits of fixed rules versus discretionary policies. Monetary economists investigated the relative merits of different ultimate and intermediate targets and of different instruments. The literature on optimal control suggested that rules need not be simple as, say, Milton Friedman preferred, but could be feedback rules allowing for nuanced responses to different contingencies. The second feature was that orthodox policy analysis was typically conducted in the context of large-scale macroeconometric models.

In the 1970s, the orthodoxy was attacked on two separate fronts. These two fronts are related, although their relationship is sometimes not clearly understood. The first front is the new-classical policy analysis of Robert Lucas and others. The second is the program of VARs initiated by Christopher Sims.

In the early 1970s, the early new classical school, especially as represented in the work of Lucas, attacked the logic of orthodox policy analysis. Before Lucas, economists typically analyzed the economy and the policymaker as independent. A policymaker who understood the economy (through a large macroeconometric model) could choose instrument settings and use the model to predict outcomes. Lucas $(1972,1976 a)$ insisted that a sound analysis of policy required that the economy and the policymaker be seen as interdependent. The public based its behavior on its expectations of the policymaker's actions derived from an understanding of the rules that the policymaker followed. The rational-expectations hypothesis is a crisp implementation of the assumption that the public understands the implications of the policy rule. The public is modeled as having expectations that are consistent with the outcomes that would be predicted by the model of the economy itself. The policymaker cannot, then, model the public as being misled about the implications of systematic policies.

Lucas joined the rational-expectations hypothesis to the assumption of continuous market clearing and monetary neutrality to underwrite the "surprise-only" analysis of aggregate supply. On this view, money has no effect except when the public mistakes neutral changes in the price level for economically significant changes in relative prices; the rational-expectations hypothesis (Muth 1961) guarantees that such mistakes are short-lived.

Lucas not only undermined the conviction that systematic policy could be useful, he provided a basis for dismissing the usefulness of the typical macroeconometric models of the day as engines of policy analysis. The common practice circa 1970 was to use aggregative models with equations estimated conditionally on the existing monetary institutions and then to assume that the coefficients of the models remained constant as policymakers altered the values of monetary-policy variables and worked out their implications for GDP or other variables of interest. The surprise-only aggregatesupply function implied that this was a useless strategy. And Lucas predicted that one would find evidence of its uselessness in the instability of the coefficient estimates in macroeconometric models: as monetary regimes changed - that is, as the rules of systematic monetary policy changed-the coefficient estimates would also change.

The notion that changing the policy rule could not usefully affect real target variables became known as the policy-ineffectiveness proposition (Sargent and Wallace, 1975, 1976), while the conclusion that the coefficient estimates would change as policy regimes changed became known as the policy-noninvariance proposition or the Lucas critique. Although the Lucas critique is sometimes seen to be an attack on a modeling strategy (without rational expectations, the macroeconometric modeler cannot get it right), Lucas's point is not "if we only knew how the estimates would change, we could continue to use the old strategy of policy analysis." Rather, the point is that the estimates of the coefficients are merely shifting and useless correlations among macroeconomic aggregates. The real attack on macromodels is the policyineffectiveness proposition, which implies that there is no point in getting it right anyway: the surprise-only/rational-expectations hypothesis already implies that no predictable policy could work. Given policy ineffectiveness, the Lucas critique is a sideshow with respect to aggregate demand policies.

Over the past 25 years, the Lucas critique has become entrenched wisdom among macroeconomists. In contrast, the foundations of the surpriseonly analysis of aggregate supply have been attacked in various ways. One approach challenges fundamental features of Lucas's analysis-particularly, the rational-expectations hypothesis or rapid market clearing. Lucas (1972) himself had pointed out that, if expectations were formed adaptively, systematic monetary policy would have real effects. Fischer (1977), Phelps and Taylor (1977), Taylor (1979), and, more recently, Fuhrer and Moore (1995) 
and Rotemberg $(1982,1996)$, among others, have shown that, if prices can adjust only slowly because of contracts or because of costs of adjustment, then systematic monetary policy, not just monetary surprises, will have real effects.

A second approach developed more slowly out of the new classical analysis itself. Initial empirical tests of Lucas's analysis appeared to support the surprise-only hypothesis (Lucas, 1973, and Barro, $1977,1978)$. Lucas (1973) himself realized that monetary surprises alone could not describe the serial correlation of output characteristics of the business cycle. He hypothesized non-monetary mechanisms involving optimal investment and intertemporal substitution in labor supply that would propagate an initial monetary shock through time (Lucas, 1975). More detailed investigations of the monetary-surprise hypothesis, however, revealed anomalies (Barro and Rush, 1980, and Gordon, 1990, p. 1135). Investigations of the stationarity of macroeconomic aggregates (Nelson and Plosser, 1982) convinced many macroeconomists that monetary shocks could not account for business cycles. If money were neutral in the long-run it could not induce permanent changes in real variables. Yet real output was, in fact, dominated by a non-stationary component, suggesting that real rather than monetary shocks were the cause of its movements. Kydland and Prescott's (1982) claim, that a business-cycle model with only real shocks better explained the data than a model with monetary shocks, bolstered this time-series result. In one of the main streams of macroeconomic development, monetary policy came to be viewed as irrelevant. The rational-expectations hypothesis and the principle of the Lucas critique were nonetheless now entrenched.

Sims (1980) criticized the orthodoxy of pre1970 s policy analysis along a second front. A central problem in isolating the independent causes of changes in macroeconomic aggregates is that the data are highly intercorrelated. The ideal of orthodox modelers was the strategy developed by the Cowles Commission in the late 1940s and early 1950s (see Morgan, 1990, and Hendry and Morgan, 1995, parts IV and VII and the correlative sections of the introduction). The hope was to isolate invariant (causal) structures using the implications of well-grounded economic theory to provide strong identifying restrictions. In practice, identifying restrictions were often imposed without firm justification. Sims (1980) played the honest boy gazing on the emperor of orthodox macroeconometric modeling, loudly declaring that he could see no clothes. The usual identifying assumptions were literally "incredible" - neither derivable from economic theory nor plausible on other grounds.

Sims's attack was not grounded in the new classical analysis or the Lucas critique, but was an independent criticism of the orthodox modeling. Nonetheless, one reaction to the Lucas critique can be seen as an attempt to answer Sims as wellto provide credible identifying restrictions. One way of dealing with coefficients that shift with changing monetary-policy regimes is to provide an accurate accounting of the actual behavior of the policymaker and the public in terms of the so-called "deep parameters" governing tastes and technology and economic constraints. The idea is to provide a detailed, structural model of the economy grounded in individual decision-making. Although this approach - at least in its representative-agent model form - dominates theoretical macroeconomics today, it has not been a notable empirical success. It founders because it makes a giant, unwarranted leap in concluding that what might be captured in a model of unique and differentiated individuals can be scaled up to an aggregate - the representative agent - that behaves just like one of the individuals, only on the scale of the whole economy. The identifying assumptions derived on such a basis are just as incredible as any palmed off by "structural" econometric modelers even before the dawn of the new classical macroeconomics. ${ }^{1}$

Sims's alternative program eschewed identification and worked instead with unrestricted reduced-form equations-VARs. Every variable in the VAR is regarded as endogenous. Each variable in the vector of endogenous variables is regressed on lagged values of itself and of all of the other variables. The VAR decomposes the observed variation in the economy into random errors and systematic responses. Since the variables are all endogenous, the action in the economy is attributed to the random-error terms. But Sims realized that these errors were not themselves exogenous as they were likely to be correlated with one another. Several simple algebraic transformations of the VAR could provide decompositions in which the errors were no longer intercorrelated by con-

\footnotetext{
1 Hansen and Sargent (1980) provide a classic example of this strategy. See Kirman (1992), Hartley (1997), and Hoover (2001a, Lecture 3) for criticism of the representative-agent assumption.
} 
struction. Then policy analysis could concentrate on the transformed error terms. These are the exogenous "shocks." In the transformed system, one could easily trace out the endogenous responses to the exogenous shocks in impulse-response functions or quantify their influence in variance decompositions.

The difficulty with this strategy is that the orthogonalizing transformations are not unique, but form an observationally equivalent class. To choose one of the transformations from the equivalence class is to impose structure on the model. ${ }^{2}$ Each transformation defines quantitatively different shocks and different responses of endogenous variables to the shocks. The implications of a shock to monetary policy will generally be different depending on which transformation is chosen.

Noting the problem of observational equivalence, Cooley and LeRoy (1985) and Leamer (1985) argued that VARs were useful for policy analysis only to the degree that they were themselves structural. Sims conceded the point, but only by degrees. The key point in breaking down observational equivalence was to eliminate the correlation among the non-orthogonalized shocks. This required structural assumptions only about the contemporaneous variables. So-called "structural VARs" retain unrestricted lagged variables. ${ }^{3}$ But even the contemporaneous order needs just as much justification as any other identifying assumption if it is not to be incredible. Yet the arguments that typically support the presumed order are informal or even casual. Credibility lies in the eye of the modeler.

The relationship of the program of VARs to the new classical macroeconomics was not completely worked out. Impulse-response functions modeled monetary surprises in a manner analogous to Lucas's surprise-only approach. Sims $(1982,1986)$ defended the structural VAR approach from the Lucas critique with the argument that the practice of monetary policy is captured in stable (if possibly complicated) contingent rules that change only rarely. Within any stable policy regime, the Lucas critique would not be an issue and concentrating on the response of the economy to shocks would be the appropriate strategy.

Most quantitative analysis of monetary policy is now conducted using VARs. But should it be? If Lucas was right in the first place, how does knowing the response of the economy to shocks help the policymaker when shocks cannot be systematically exploited? We cannot help but think that some practitioners want to have it both ways: to have a method that is immune to the Lucas critique because its VARs are estimated over periods in which, in fact, there have been no regime changes and, at the same time, to formulate advice for systematic policy on the basis of the impulse-response functions of these VARs. ${ }^{4}$

Recently policy analysis using VARs has moved past an exclusive focus on impulse-response functions and variance decomposition. Observing that only a small amount of the variability of the target variables in the economy can be credited to the shocks in monetary instruments no matter how they are identified, several economists have sought to shift the focus to systematic policy rules. ${ }^{5}$ For example, one might ask how much of the response of the economy to a non-monetary shock (e.g., to an oil-price shock) is direct and how much is induced by the response of monetary policy to the shock?

Bernanke, Gertler, and Watson (1997), for example, estimate a structural VAR and then trace out the impulse responses when the equation governing the monetary instrument is modified to follow the desired rule. Sims (1999), in another example, imposes a structure that allows him to isolate the equations governing monetary policy in such a way that he believes he can legitimately transfer them from a VAR estimated on recent data to one estimated on data from before World War II. He asks whether the economy of the 1920s and 1930 s would have developed differently if monetary policy in the earlier period had followed the

\footnotetext{
2 The transformations are observationally equivalent in the sense that, having the same reduced form, they also have the same likelihood. From the 1940s through the mid-1960s, whether systems of structural equations should be specified recursively or simultaneously was hotly debated (Wold 1960). The debate fizzled when Robert Basmann (1965) demonstrated the observational equivalence of recursive and simultaneous systems.

3 That is, unrestricted aside from the practical necessity of a finite number of lags.

4 See Cooley, LeRoy, and Raymon (1984) and LeRoy (1995) for an argument that the practice is, in fact, legitimate. Cf. Hoover (1988, Chap. 8, Section 4; 2001b, Chap. 7, Section 4).

5 Some notable recent papers in this vein are Taylor (1995), Rotemberg and Woodford (1997, 1998), Bernanke, Gertler, and Watson (1997), and McCallum (1999). In the VARs reported in Section V, the usual variance decomposition attributes between 0.8 percent and 31 percent of the variance at a one-year horizon (depending on the estimation period) to the monetary shock. Because the variance attributable to each of the shocks mixes the direct effect of the random shocks with the indirect effects of the deterministic structural elements of the VAR, these estimates form an upper bound on the real effects attributable to unsystematic monetary policy.
} 
typical patterns of the later period. Both examples are extensions that do not fundamentally change the structural-VAR framework. But inconsistencies remain. If Lucas's earlier assessment of monetary policy analysis is correct, which appears to be the unstated assumption of the emphasis on shocks (see Sections II and IV), then the counterfactual experiments are pointless. On the one hand, if the economy is really governed by a surprise-only aggregatesupply function and people have rational expectations, systematic policy, regardless of how it reacts to exogenous shocks, is ineffective. On the other hand, if policy regimes change, then the structural VARs should be just as subject to the Lucas critique as earlier "structural" macroeconometric models.

Our goal is to take a step to deal with these inconsistencies, to assess monetary policy in a VAR framework in a way that accounts for (or, if appropriate, dismisses) Lucas's analysis of policy. Our approach is based on an empirical implementation of Cochrane's (1998) structural interpretation of VARs. A by-product of the exercise is a framework for a critical assessment of the ways VARs are used for policy analysis.

\section{A TAXONOMY OF MONETARY POLICY}

\section{The VAR and the Structural VAR}

Monetary policy analysis involves at least two connected distinctions: systematic versus unsystematic policy and anticipated versus unanticipated policy. To clarify the relationships among these distinctions and their role in policy analysis, we develop a stripped-down VAR model and relate it to an equally stripped down macromodel.

We begin with the VAR. Two variables, which we think of as output $\left(y_{t}\right)$ and money $\left(m_{t}\right)$, depend on the histories of both variables and on random errors $\omega_{t}^{\prime}=\left(\omega_{y t}, \omega_{m t}\right)$. For simplicity, we consider only one lag of the variables:

$$
\begin{aligned}
& y_{t}=\theta_{y y} y_{t-1}+\theta_{y m} m_{t-1}+\omega_{y t} \\
& m_{t}=\theta_{m y} y_{t-1}+\theta_{m m} m_{t-1}+\omega_{m t} .
\end{aligned}
$$

The covariance matrix of these errors is:

$$
E\left(\boldsymbol{\omega}_{t} \boldsymbol{\omega}_{t}^{\prime}\right)=\left[\begin{array}{cc}
\operatorname{var}\left(w_{y t}\right) & \operatorname{cov}\left(w_{y t}, w_{m t}\right) \\
\operatorname{cov}\left(w_{y t}, w_{m t}\right) & \operatorname{var}\left(w_{m t}\right)
\end{array}\right] .
$$

Since there is no reason to believe that the error terms in equations (1) and (2) are not correlated, the off-diagonal terms are in general not zero. This poses a problem for policy analysis since it implies that we cannot distinguish the shocks: a shock, say, to the money equation would in general be associated with a correlated shock to the output equation. A properly transformed system, however, would fit the data equally well and have independent error terms. For example, multiply equation (2) by $\mu=\operatorname{cov}\left(\omega_{y t}, \omega_{m t}\right) / \operatorname{var}\left(\omega_{m t}\right)$ and subtract it from equation (1) to yield:

$$
y_{t}=\Pi_{0} m_{t}+\Pi_{1} m_{t-1}+\Pi_{2} y_{t-1}+\xi_{y t}
$$

where

$$
\begin{aligned}
& \Pi_{0}+\mu \\
& \Pi_{1}=\theta_{y y}-\mu \theta_{m m} \\
& \Pi_{2}=\phi_{y m}-\mu \phi_{m m} \\
& \xi_{y t}=\omega_{y t}-\mu \omega_{m t} .
\end{aligned}
$$

Equations (2) and (4) constitute a transformed model for which the random-error terms

$$
\xi_{t}^{\prime}=\left(\xi_{y t}, \omega_{m t}\right)
$$

are no longer correlated:

(5) $E\left(\xi_{t} \xi_{t}^{\prime}\right)=$

$$
\left[\begin{array}{cc}
\operatorname{var}\left(\omega_{y t}\right)-2 \operatorname{cov}\left(\omega_{y t}, \omega_{m t}\right)+\mu^{2} \operatorname{var}\left(\omega_{m t}\right) & 0 \\
0 & \operatorname{var}\left(\omega_{m t}\right)
\end{array}\right] .
$$

This transformation is the bivariate version of the Choleski factorization. It is characterized by the transformation of the variance-covariance matrix into a diagonal form and by the recursive structure of the contemporaneous variables known as the Wold causal order. Money is causally ordered ahead of output because $m_{t}$ appears in equation (4) and helps to determine $y_{t}$, whereas $y_{t}$ does not appear in equation (2). The lack of correlation between the random-error terms in the transformed system means that each equation may be shocked independently. The Wold causal order means that shocks to money transmit immediately to output, but shocks to output transmit to money only with a lag.

Unfortunately the Choleski factorization is not unique. If instead we had multiplied equation (1) by $\delta=\operatorname{cov}\left(\omega_{y t}, \omega_{m t}\right) / \operatorname{var}\left(\omega_{y t}\right)$ and subtracted it from 
equation (2), we would have ended up with a system with a diagonal variance-covariance matrix, albeit with different error terms, and a Wold causal order in which output was ordered ahead of money. This is the problem of observational equivalence.

The VAR setup here is easily generalized to longer lags and more variables. Higher dimensional VARs will have as many Choleski factorizations as there are permutations of the variables. Furthermore, the restrictions that diagonalize the variancecovariance matrix need not be Choleski, and the equations of the transformed model need not be strictly recursive. The rule is that the system is identified so long as there are at least as many restrictions as the number that would be imposed by a Choleski decomposition, that is, $n(n-1) / 2$. When the modeler claims that the particular order of the contemporaneous variables is the true one, the model is known as a structural VAR. ${ }^{6}$ If the claim is warranted, then we have the pleasant result of having isolated the true independent shocks to the variables. When it is unwarranted, the shockseven though uncorrelated by construction-are linear combinations of the true shocks.

The word "structural" here refers only to the relatively weak notion of an ordering of contemporaneous variables. The lagged variables remain unordered (and, in a commonsense usage, nonstructural). Yet, "structural VAR" in this sense has become cast-iron idiom. We will distinguish between structural VARs and structural macroeconomic (or macroeconometric) models in which the invariant parameters are identified.

Each shock to the VAR system has several effects: (i) a direct effect on the current value of the dependent variable in its own equation; (ii) an effect mediated through that variable on any equation lower in the causal order; and (iii) an infinite sequence of effects on the future values of both variables, since the values of today become the lagged values of tomorrow. The impulse-response function for the system of equations (2) and (4) captures the net result of all three effects. It is calculated by repeatedly substituting the lagged values of one equation into the other to eliminate the variables, leaving only the error terms going infinitely far back. This is the moving-average representation of the system. Although, in principle, the movingaverage representation involves infinitely many shock terms, it is, in practice, truncated to some finite number. Typically, the impulse-response function is represented by a graph of the effect of a single-period unit shock on one of the variables over time. In principle, impulse-response functions are not invariant to the causal order of the structural VAR, so that getting the causal order correct is critical.

\section{The Structural Macroeconometric Model}

We begin the exposition of the structural macroeconometric model with a textbook Lucasian model. Output measured as a deviation from the mean is governed by a surprise-only aggregatesupply curve in which output at time $t\left(y_{t}\right)$ depends on the deviation of prices $\left(p_{t}\right)$ from prices that were expected at $t-1$ to hold at $t\left(p_{t}^{e}\right)$ :

$$
y_{t}=\alpha\left(p_{t}-p_{t}^{e}\right)+\varepsilon_{y t},
$$

where $\varepsilon_{y t}$ is a white-noise error term, and all variables are expressed in logarithms. Aggregate demand is assumed for convenience to be governed by a quantity equation with velocity normalized to unity:

$$
p_{t}=m_{t}-y_{t},
$$

where $m_{t}$ is the money stock, which is assumed to be in the control of the monetary authorities and governed by a monetary-policy rule (or reaction function):

$$
m_{t}=\gamma_{1} m_{t-1}+\gamma_{2} y_{t-1}+\varepsilon_{m t},
$$

where $\varepsilon_{m t}$ is a white-noise error term independent of $\varepsilon_{y t}$. This policy rule is a feedback rule that allows the monetary authorities to react to the state of the real economy, as well as to past values of the money stock. The model is closed by assuming that price expectations are formed rationally on the basis of all the information available up to time $t-1\left(\Omega_{t-1}\right)$ :

$$
p_{t}^{e}=E\left(p_{t} \mid \Omega_{t-1}\right) \text {. }
$$

The distinction between systematic and unsystematic monetary policy refers to the policymaker. In the reaction function, equation (8), systematic policy is characterized by the choice of policy parameters, $\gamma_{1}$ and $\gamma_{2}$, while unsystematic policy is

\footnotetext{
6 In the simple two-variable example, there are just two Choleski orderings and one further overidentified ordering in which the contemporaneous value of neither variable appears in the two equations (i.e., the ordinary VAR turns out to be the structural VAR). In larger systems, even when just identified or overidentified, there may be blocks of simultaneous equations.
} 


\section{Table 1}

\section{A Taxonomy of Monetary Policy}

\begin{tabular}{c|lcr}
\multicolumn{2}{c}{} & \multicolumn{2}{c}{ Policymaker } \\
\cline { 3 - 4 } Public & Anticipated & Snown policy-reaction function & Unsystematic \\
\hline Unanticipated & $\begin{array}{c}\text { Surprise change to new known policy- } \\
\text { reaction function }\end{array}$ & $\begin{array}{r}\text { Credible announcement of a transitory, } \\
\text { atypical setting of a policy instrument } \\
\text { Random shock to policy-reaction function }\end{array}$
\end{tabular}

characterized by the error term, $\varepsilon_{m t}$. The distinction between anticipated and unanticipated monetary policy refers to the public. In equation (6), a policy is unanticipated if it delivers a non-zero price surprise $\left(p_{t}-p_{t}^{e} \neq 0\right)$; it is anticipated if it delivers no price surprise $\left(p_{t}-p_{t}^{e}=0\right)$.

The two distinctions can be thought of as forming a two-by-two matrix as in Table 1. Each cell provides an example of the type of policy that exemplifies it. The fact that the cells along the main diagonal illustrate the most common monetarypolicy actions explains the frequent equivocation between systematic and anticipated policies, on the one hand, and unsystematic and unanticipated policies, on the other. Policies are usually paired in those ways. Yet, surprisingly, neither of the offdiagonal cells is empty. One might think at first blush that unsystematic monetary policy could not be anticipated. Yet, if we regard the systematic elements of the reaction function as capturing what the monetary authorities typically do, we can imagine a transitory policy action which is both atypical—and, therefore, unsystematic - and yet widely expected. Past and future Federal Reserve behavior, for example, may in the current circumstances point to a 0.25 point rise in the federal funds rate; yet, the Federal Reserve may raise rates 0.5 points, as might have been widely expected, thus causing no surprise. The injection of liquidity in anticipation of the so-called "Y2K" demand may provide a less generic example. We can distinguish between anticipated and unanticipated policy according to whether the policy is fully captured in $\Omega_{t-1}$. If a transitory policy were captured in $\varepsilon_{m t}$, but $\varepsilon_{m t}$ was in fact effectively an element of $\Omega_{t-1}$, there would be no price surprise in equation (6).

The usual solution to a model such as that in equations (6) through (9) presumes that only information dated at $t-1$ or before can be part of the information set, $\Omega_{t-1}$. On that assumption, the model can be solved for $y$ :

$$
y_{t}=\left(\frac{1}{1+\alpha}\right)\left(\alpha m_{t}-\alpha y_{1} m_{t-1}-\alpha \gamma_{2} y_{t-1}+\varepsilon_{y t}\right) \text {. }
$$

Despite the apparent influence of $m$ over $y$, systematic policy is ineffective. To see this, substitute equation (8) into (10), to yield:

$$
y_{t}=\left(\frac{1}{1+\alpha}\right)\left(\alpha \varepsilon_{m t}+\varepsilon_{y t}\right) .
$$

Only the real shock to aggregate supply and $\varepsilon_{m t}$, the unsystematic part of monetary policy, and not the systematic part (governed by $\gamma_{1}$ and $\gamma_{2}$ ) matter.

Equations (8) and (10) can be regarded as a structural VAR with $m$ (Wold-)causally ordered ahead of $y$. Equation (11) can be regarded as a (degenerate) form of the moving-average representation of this VAR. The impulse-response function for $y$ to a unit monetary shock follows from equation (11) and takes the value $(1+\alpha)^{-1}$ at period $t$, and zero thereafter. In this case, it is easy to see that the usual method assumes the monetary-policy action is both unsystematic and unanticipated. This case illustrates the policy-ineffectiveness proposition.

Contrast this to the case in which the monetarypolicy action is unsystematic and anticipated. As we already noted, an unsystematic, anticipated policy is equivalent to $\Omega_{t-1}$ including $\varepsilon_{m t}$. When $\varepsilon_{m t}$ is not known at $t-1$, the rational expectation of $m_{t}$ is $\gamma_{1} m_{t-1}+\gamma_{2} y_{t-1}$; but, when $\varepsilon_{m t}$ is known at $t-1$, it is simply $m_{t}$. An easy way to derive the consequence for $y$ of an anticipated, unsystematic policy is to replace $\gamma_{1} m_{t-1}+\gamma_{2} y_{t-1}$ with $m_{t}$ in equation (10) to yield:

$$
y_{t}=\left(\frac{1}{1+\alpha}\right) \varepsilon_{y t} .
$$

The impulse response to an unsystematic shock to 
monetary policy is now zero for all current and future times because the impulse is itself eliminated, that is, $\left(p_{t}-p_{t}^{e}=0\right)$.

\section{Mapping Between the Structural Macroeconometric Model and the Structural VAR}

Turning to systematic policy, notice that an econometrician typically would not estimate a regression of the form of equation (10). Rather he would estimate something like equation (4). The coefficients of equation (4) can be related to the parameters of the structural macroeconomic model:

$$
\begin{aligned}
& \Pi_{0}=\frac{\alpha}{1+\alpha} \\
& \Pi_{1}=\frac{\alpha \gamma_{1}}{1+\alpha} \\
& \Pi_{2}=\frac{\alpha \gamma_{2}}{1+\alpha} \\
& \xi_{y t}=\frac{1}{1+\alpha} \varepsilon_{y t} .
\end{aligned}
$$

If equations (6) through (9) are the true model, then the two sets of equations (4a) through (4d) and (4a') through $\left(4 d^{\prime}\right)$ together provide a mapping between the true underlying parameters of the structural macroeconomic model and the reduced-form coefficients of the ordinary VAR. Given the ethos of the structural VAR program, the assumption one knows that equations (6) through (9) are the true model is too strong to be believed. Yet, without this assumption, the constituent parameters $\left(\alpha, \gamma_{1}, \gamma_{2}\right)$ cannot be identified separately. ${ }^{7}$ A change in systematic policy, a change in the value of $\gamma_{1}$ or $\gamma_{2}$, will change the value of one or more of the $\Pi_{i}$ 's. This is the Lucas critique: the estimated macroeconometric relationship is not invariant to changes in systematic policy. Such a policy change, however, could have a real effect only to the degree that it was unanticipated. If the change were credibly announced in advance, then like other anticipated policies it would have no effect. If it were sprung on the public by surprise, it would act like an unanticipated shock until it was incorporated into the public's expectations (see the lower left-hand cell of Table 1).

The Lucas critique might appear to threaten the usefulness of the VAR methodology in the case of changing monetary regimes-since every shift of systematic policy would alter not only the monetarypolicy equation (equation (8)) but also the rest of the system (here equation (4) with the coefficients defined by $\left(4 a^{\prime}\right)$ through $\left.\left(4 d^{\prime}\right)\right)$. While it is true that the coefficients (the $\Pi_{i}$ 's) will change (that is, the structural VAR is non-invariant), both equations (11) and $\left(10^{\prime}\right)$ (the moving-average representation of the structural VAR) are invariant to the policy regime. They depend only on the parameter $\alpha$, which is not a parameter of the policy-reaction function. The invariance of the moving-average representations implies that the impulse-response functions are themselves invariant. The VAR is immune to the Lucas critique not because regimes do not in fact change but because of the assumptions that real variables respond only to monetary surprises and that expectations are rational. Since equation (11) is drawn from a transformation of the structural VAR, the invariance result depends on having the correct structural VAR. Getting the right causal structure of the contemporaneous variables is, therefore, crucial.

\section{RULE-OF-THUMB AND PARTIAL RATIONAL MODELS}

Although it is not often remarked, the manner in which VARs are usually evaluated makes sense on the assumption that Lucas's analysis of monetary policy is correct. What is more, only the case of unsystematic, unanticipated monetary policy is typically analyzed. This is the case of the policyineffectiveness proposition in full force. An older tradition saw monetary policy as having real effects, either because expectations were not formed rationally or because prices did not move quickly to clear markets. To incorporate this view into the model of the last section, we could replace equation (9) with an adaptive-expectation scheme. This would be analogous to Lucas's non-natural rate model, the foil for the rational-expectations model of his 1972 paper. Or we could add a price adjustment equation, which is the approach implicit in the overlapping contract models and explicit in the models of Fuhrer and Moore (1995) and Rotemberg (1982, 1996), among others. A less specific approach would be to model anticipated monetary policy more simply as directly affecting output. Instead of equation (6), aggregate supply is modeled as

$$
y_{t}=\beta m_{t}+\varepsilon_{y t} \text {. }
$$

Now equations (8) and (12) form a structural VAR.

\footnotetext{
7 If we are willing to assume the truth of the model, then $\gamma_{1}=\Pi_{1} / \Pi_{2}$, $\alpha=\left(1+\Pi_{0}\right)^{-1}$, etc.
} 
In the new system, the distinction between anticipated and unanticipated monetary policy is mootboth have an identical effect on $y$. Similarly, the Lucas critique is inapplicable since equation (12) indicates that expectations are not an element in people's supply responses.

The two systems (equations (8) and (10) and equations (8) and (12)) represent extreme cases. Cochrane (1998) considers an intermediate case in which there are two types of agents in the economy: Lucasian agents, who have rational expectations and act according to equations (6) and (9), and those who do not have rational expectations and act according to equation (12). Following his conjecture in a simplified case, we characterize an economy with both types as a simple mixture of equations (6) and (12), where $\lambda$ is the mixing parameter:

$$
y_{t}=\lambda \beta m_{t}+(1-\lambda) \alpha\left(p_{t}-p_{t}^{e}\right)+\varepsilon_{y t} .
$$

Intuitively, we can regard $(1-\lambda)$ as the proportion of people in the economy who form rational expectations and $\lambda$ as the proportion who follow a rule of thumb. ${ }^{8}$ But this is not quite right since those forming rational expectations would rationally take account of the responses of those who follow a rule of thumb, so that $\lambda$ would properly correspond to the proportions of the two groups only if they lived on separate islands. It may nonetheless satisfactorily capture the relative importance of their behaviors (if not their numbers) and, when properly selected, may adequately account for the properties of the impulse-response functions of the estimated VAR. ${ }^{9}$

The complete model consists, then, of equations (7), (8), (9), and (13). The new system is given by the solution for $y$ (equation 14) and the policy rule in equation (8), namely,

$$
\begin{aligned}
& y_{t}=\left[\frac{\lambda \beta+(1-\lambda) \alpha}{1+(1-\lambda) \alpha}\right] m_{t} \\
&-\left[\frac{(1-\lambda)(1-\lambda \beta) \alpha}{1+(1-\lambda) \alpha}\right]\left(\gamma_{1} m_{t-1}+\gamma_{2} y_{t-1}\right) \\
&+\left[\frac{1}{1+(1-\gamma) \alpha}\right] \varepsilon_{y t} \\
& m_{t}=\gamma_{1} m_{t-1}+\gamma_{2} y_{t-1}+\varepsilon_{m t} .
\end{aligned}
$$

When $\lambda=1$, equation (14) reduces to equation (12); and when $\lambda=0$, it reduces to equation (10). In gen- eral, when $0<\lambda<1$, equations (8) and (14) form a structural VAR.

Because of the interaction between agents with rational expectations and those for whom the distinction between anticipated and unanticipated monetary policy is meaningless, the Lucas critique has real bite, except in the two extreme cases. Not only are the estimates of the structural equations (8) and (14) not invariant, the responses of $y$ to monetary impulses are complicated functions of the mixing parameter, $\lambda$, as well as the policy parameters, $\gamma_{1}$ and $\gamma_{2}$. What is worse for purposes of empirical analysis is that, in a single regime (that is, for a particular setting of the policy parameters), $\lambda$ is not identified and cannot be estimated directly. The inability to measure $\lambda$ renders Cochrane's analysis critical rather than empirical. Cochrane (1998) illustrates the consequences of different assumptions about the value of $\lambda$ but provides no means of getting an empirical handle on it.

To make some headway, notice that, when policy is anticipated and we can, therefore, replace $\gamma_{1} m_{t-1}+\gamma_{2} y_{t-1}$ with $m_{t}$, equation (14) reduces to

$$
y_{t}=\lambda \beta m_{t}+\left(\frac{1}{1+(1-\lambda) \alpha}\right) \varepsilon_{y t} .
$$

Equation (15) is invariant to monetary-policy regime but depends on the mixing parameter, $\lambda$. If we assume that $\lambda$ is itself invariant to regime changes as seems reasonable, then regime changes themselves can be used to identify $\lambda$. Intuitively, the identification strategy works like this: A structural VAR (analogous to equations (8) and (14)) is estimated in two or more regimes. In general, the impulse-response functions can be worked out from the moving-average representation of the structural VAR only if we assume a value for $\lambda$; and, thus, the impulse-response functions will be different for every different $\lambda$. But since, according to equation (15), the impulse response to an anticipated monetary shock should be identical across regimes, we

8 This is similar to Campbell and Mankiw's (1989) consumption function in which one part of the population follows the permanentincome hypothesis and another part follows a rule of thumb.

9 The interaction in which the rational agents take account of the responses of the non-rational agents is part of Haltiwanger and Waldman's (1989) analysis. In work on the consumption function, Haase (1998) demonstrates that the likely difference between a proper analysis of the interaction and a pure mixing process is likely to be small, so that in this case $\lambda$ is probably very close to the actual proportion of the population that does not exhibit rationalexpectations/surprise-only aggregate supply behavior. 
search for that value of $\lambda$ that delivers the required identity. The details of our implementation strategy are set out in the next section.

\section{MEASUREMENT STRATEGY}

\section{Deeper Structures}

The model of the last section was simplified to illuminate the taxonomy of monetary policy more clearly. To carry the strategy just sketched to the data, we need a more complicated model. Closely following Cochrane (1998), we generalize the model in two ways: first, we allow interactions with a set of macroeconomic variables orthogonal to the monetary shocks; second, we allow for the richer dynamics characteristic of the VAR approach. The final setup is designed to accommodate any macroeconomic model that can be well represented empirically by a VAR.

The main focus of our approach is Cochrane's (1998) equation (8), reproduced here with a slight change of notation as

$$
y_{t}=A(L)\left[\lambda m_{t}+(1-\lambda)\left(m_{t}-E\left(m_{t} \mid \Omega_{t-1}\right)\right)\right]+\boldsymbol{B}(L) \boldsymbol{\varepsilon}_{w t},
$$

where $y_{t}$ denotes an output measure that belongs to a vector of non-monetary variables $w, m_{t}$ denotes a monetary-policy indicator, $E(. \mid$.) is the conditional expectations operator, $\Omega_{t-1}$ is the information available at time $t-1$, and $\boldsymbol{\varepsilon}_{w t}$ is a vector of orthogonalized, non-monetary innovations (which include the output innovation itself). The term $A(L)$ is a polynomial in the lag operator $L$ (e.g., $L^{\alpha} x_{t}=x_{t-\alpha}$ ). $B(L)$ is a polynomial vector in the lag operator. The parameter $\lambda$ takes values between 0 and 1 .

Equation (13) is a particular case of equation (16). Equations (7) and (9) can be used to eliminate the term $\left(p_{t}-p_{t}^{e}\right)$ in equation (13), replacing it with the term $\left(m_{t}-m_{t}^{e}\right)$. Equation (13) has no intrinsic dynamics. The dynamics of the system of equations (7) through (9) and (13) come entirely from the dynamics of the monetary-policy rule (equation (8)). In contrast, the lag structure $A(L)$ provides equation (16) with its own dynamics. The parameters $\alpha$ and $\beta$ in equation (13) are subsumed in $A(L)$. The form of the equation reflects a conception of the influence of monetary policy in which either an anticipated shock $\left(\lambda m_{t}\right)$ or an unanticipated shock $\left((1-\lambda)\left(m_{t}-m_{t}^{e}\right)\right)$ is propagated by exactly the same mechanism: $A(L)$. Non-monetary impulses propagate according to their own mechanism: $\boldsymbol{B}(L)$.
Note that, although we have been drawing a parallelism between equation (13) and equation (16), the latter is silent with regard to the causal structure of the underlying model (despite the presence of the term $\lambda m_{t}$ ). It is a general expression that does not restrict the modeler's choice of structural identification assumptions in any way. This point is made transparent in the derivation of equation (20) below. Equation (16) can be rewritten as

(17)

$$
\begin{aligned}
y_{t} & =\lambda A(L) E\left(m_{t} \mid \Omega_{t-1}\right)+A(L)\left[m_{t}-E\left(m_{t} \mid \Omega_{t-1}\right)\right] \\
& +\boldsymbol{B}(L) \boldsymbol{\varepsilon}_{w t},
\end{aligned}
$$

which makes its economic interpretation easier. The term $\lambda A(L)$ describes the dynamic response of output to anticipated monetary policy, $E\left(m_{t} \mid \Omega_{t-1}\right)$. In a Lucasian economy in which everyone has rational expectations, $\lambda=0$ and the first term of the right-hand side of equation (17) vanishes. The term $A(L)$ describes the dynamic response to unanticipated monetary policy $\left(m_{t}-E\left(m_{t} \mid \Omega_{t-1}\right)\right)$.

Equation (16) captures the spirit of early aggregate new classical models. Yet, it falls short of the quest initiated with Lucas's (1976a) "critique" for a model grounded in tastes and technology-a true microfoundational model. That quest, we believe, is quixotic. Either it is hopelessly intractabletheoretically and empirically -if one seeks to model millions of individuals, or it is of dubious empirical relevance if one falls back on the representativeagent (or even agents) assumption. To bring the representative-agent model to aggregate data in the form of maintained identifying assumptions is to impose restrictions that implicitly claim that the aggregates behave as if they were governed by an individual scaled-up to the size of the economy. Such a claim beggars belief; it is far more incredible than anything assumed by the macroeconometric modelers of the 1960s. ${ }^{10}$

We believe that the Lucas critique can be dealt with only pragmatically. We cannot seek invariance at the deepest microfoundational level, but we must rather seek relative invariance a level or two below the aggregate macroeconomic phenomena. The parameters of a structural VAR are, we believe, unlikely to be invariant. Through some plausible, but by no means certain, assumptions, we hope to account for the most important causes of non-

\footnotetext{
${ }^{10}$ See Hoover (2001a) for a critical account of the methodological foundation of the quest for microfoundations.
} 
invariance. The only test of our assumptions is whether or not they appear to succeed in practice. Cochrane (1998) also considers a model of costly price adjustment due to Rotemberg (1982, 1996). There can be other possibly more realistic models as well. We prefer the model of equation (16) to the Rotemberg model or any of the alternatives since it makes relatively weaker (coarser) restrictions. There is a vast number of alternative models of sticky price adjustment or models using differing nonrational-expectations schemes of expectations formation in which the fine details are likely to matter a good deal. The fact that in equations (16) and (17) the anticipated/unanticipated monetary policy distinction is summarized in the single parameter, $\lambda$, is a virtue.

The key steps in our strategy of identification are to establish the links between equation (16) and the structural moving-average representation of $w_{t}$. One would first estimate the structural VAR (with the presumed-correct causal order) and then invert it to obtain

$$
y_{t}=C_{y m}(L) \varepsilon_{m t}+C_{y w}(L) \boldsymbol{\varepsilon}_{w t},
$$

where $\varepsilon_{m t}$ is the structural monetary innovation and $\boldsymbol{\varepsilon}_{w t}$ is as defined above. ${ }^{11}$ The term $C_{y m}(L)$ is an infinite polynomial, while $C_{y w}(L)$ is an infinite polynomial vector in the lag operator. Each of their elements, $c_{i, j, k}$, associates movements of variable $i$ to a shock in variable $j$ that took place $k$ periods ago. Note that, because equation (18) is a moving-average representation derived from a structural VAR, the terms $c_{i, j, 0}$ are in general non-zero for $i \neq j$. The typical Wold causal orderings that result from Choleski factorizations impose the condition $c_{i, j, 0}=0$ for all $i>j$. The observationally equivalent class is then defined by the permutations of the variables indexed by $i$ and $j$. Similarly, the moving-average representation of $m_{t}$ is,

$$
m_{t}=C_{m m}(L) \varepsilon_{m t}+\boldsymbol{C}_{m w}(L) \boldsymbol{\varepsilon}_{w t}
$$

Equating terms in expressions (17), (18), and (19), we have

(20)

$$
\begin{aligned}
& y_{t}=C_{y m}(L) \varepsilon_{m t}+\boldsymbol{C}_{y w}(L) \boldsymbol{\varepsilon}_{w t}= \\
& A(L)\left\{\lambda\left[C_{m m}(L) \varepsilon_{m t}+C_{m w}(L) \boldsymbol{\varepsilon}_{w t}\right]+(1-\lambda) c_{m m 0} \varepsilon_{m t}\right\} \\
& +\boldsymbol{B}(L) \boldsymbol{\varepsilon}_{w t},
\end{aligned}
$$

so that in general

$$
C_{y m}(L)=\lambda A(L) C_{m m}(L)+(1-\lambda) A(L) c_{m m 0}
$$

and similarly,

$$
\boldsymbol{C}_{y w}(L)=\lambda A(L) \boldsymbol{C}_{m w}(L)+\boldsymbol{B}(L)
$$

In a Lucasian economy, for which $\lambda=0$, only the unanticipated component of monetary policy has real effects resulting in

$$
C_{y m}(L)=A(L) c_{m m 0} .
$$

The factor $c_{m m 0}$ appears as a normalization that sets the 0th order coefficient on $m_{t}$ in the money equation of the VAR representation to its conventional value of unity. Equation (23) says that the structural coefficients $A(L)$ correspond to those of the usual impulse-response function of output to an orthogonalized monetary shock. Also note that $\lambda=0$ implies $C_{y w}(L)=B(L)$, that is, the response of output to each non-monetary shock characterized in the structural model by the elements of the polynomial vector $B(L)$, correspond to the usual collection of impulse-response functions in $C_{y w}(L)$. In this Lucasian case, the monetary shock is all there is to the influence of monetary policy: it starts a dynamic process going but has no further effect.

The fact that the impulse-response functions for the structural macroeconometric model in the Lucasian case of $\lambda=0$ correspond to the usual impulse response functions from the structural VAR highlights a point only infrequently acknowledged: the usual methods of assessing the implications of structural VARs implicitly assume Lucas's surprise-only economy. Looking at the other extreme case in which $\lambda=1$ demonstrates how misleading this can be. When $\lambda=1$, the equivalent to equation (23) is

$$
C_{y m}(L)=A(L) C_{m m}(L)
$$

and, similarly,

$$
C_{y w}(L)=A(L) C_{m w}(L)+B(L) .
$$

This corresponds to a traditional (pre-Lucas) structural macroeconometric model in which coefficients of the VAR representation are invariant structural parameters. Here, in contrast to the Lucasian case, a

\footnotetext{
${ }^{11}$ Equation (18) is one row of the inverted structural VAR. Other variables are represented mutatis mutandis by other rows. The derivations that follow do not require that we make specific distinction among the elements of $\varepsilon_{w}$, mainly the output shock and any other non-monetary shocks.
} 
monetary shock has a direct effect as in the Lucasian case and an indirect feedback effect in which the monetary-policy-reaction function captured in equation (19) systematically affects real variables (indicated by the terms in square brackets on the right-hand side of equation (20)).

In the intermediate case in which $\lambda \neq 0$, where some people react to anticipated monetary policy and with rational expectations integrate the behavior of these rule-of-thumb agents into their own expectations, equations (21) and (22) themselves are the equivalent to (23). In this case, the conventional impulse response of output to a shock to a variable other than money or output $\left(C_{y w}(L)\right)$ can be decomposed: the direct effect is measured by the polynomial vector $B(L)$, and the effect of the endogenous response of the monetary authority is measured by the polynomial vector $\lambda A(L) C_{m w}(L)$.

Equations (21) and (22) yield a set of conditions that govern the correspondence between the coefficients of the estimated impulse-response functions, derived from the moving-average representation of the VAR $\left(C_{i j}(L)\right)$ and the structural parameters $(\lambda, A(L)$, and $B(L)$ ). These conditions are

$$
\text { (26) } \left.\begin{array}{l}
c_{y m 0}=a_{0} c_{m m 0} \\
c_{y m 1}=a_{0} \lambda c_{m m 1}+a_{l} c_{m m 0} \\
\vdots \\
c_{y m k}=a_{0} \lambda c_{m m k}+\ldots+a_{k-1} \lambda c_{m m 1}+a_{k} c_{m m 0} \\
\vdots \\
c_{y y 0}=a_{0} \lambda c_{m y 0}+b_{0 y} \\
c_{y y 1}=a_{0} \lambda c_{m y 1}+a_{1} \lambda c_{m y 0}+b_{1 y} \\
\vdots \\
c_{y y k}=a_{0} \lambda c_{m y k}+\ldots+a_{k} \lambda c_{m y 0}+b_{k y} \\
\vdots \\
c_{y w 0}=a_{0} \lambda c_{m w 0}+b_{0 w} \\
c_{y w 1}=a_{0} \lambda c_{m w 1}+a_{1} \lambda c_{m w 0}+b_{1 w} \\
\vdots \\
c_{y w k}=a_{0} \lambda c_{m w k}+\ldots+a_{k} \lambda c_{m w 0}+b_{k w} \\
\vdots
\end{array}\right\} \text { for each } \begin{aligned}
& \\
& \text { element in } \\
&
\end{aligned}
$$

In principle, there is an infinity of such conditions; in practice, they would be truncated at some arbitrary $k=K$. Then, for any given value of $\lambda$ between 0 and 1 , one can compute the terms $a_{k}$ and $b_{i k}$ for $i \in \mathfrak{w}$ and $k=0,1,2, \ldots$, although $\lambda$ itself cannot be separately identified from the set (26).

\section{Identification Strategy}

Since $\lambda$ measures the relative importance of output responses to anticipated policy, one might quibble that more transparent and, therefore, more accurately anticipated operating procedures for monetary policy might affect the value of $\lambda$. These concerns are probably secondary. In 1994, the Federal Reserve began announcing the policy actions of the Federal Open Market Committee immediately after its meetings. Demiralp and Jordá (2000) provide evidence that financial markets already anticipated Federal Reserve policies reasonably accurately even in the period in which the actions were meant to be secret.

Although it is natural to assume that the response of output to a monetary impulse, $A(L)$, or to non-monetary shocks, $B(L)$, would remain invariant across policy regimes, one cannot rule out other sources of parameter instability unrelated to monetary policy. Such instability is a matter of econometric specification and, unlike the instability highlighted by the Lucas critique, not a matter of endogenous economic behavior. In any case, the assumption of the invariance of these dynamic structures is no stronger than the invariance assumptions typical in the literature on structural VARs.

Starting with the identifying assumptions, we must first identify distinct monetary policy regimes. Let $t=1,2, \ldots, T$ index the sample period of a time series. Let $T_{1}, \ldots, T_{H}$ denote the dates that partition the sample into $H+1$ distinct regimes corresponding to the subsamples $t=T_{h-1}+1, \ldots, T_{h}$ for $h=1, \ldots, H$. (By convention $T_{0}=0$.) Practically, the smallest of these subsamples must afford adequate degrees of freedom to estimate a monetary VAR, the specification of which is common to all subsamples but the parameters of which are estimated within each subsample. In practice, the VAR would contain the variables $y_{t}$ and $m_{t}$, along with the other variables in the vector $\boldsymbol{w}_{t}$ that are customarily included in monetary VARs. To simplify the notation and the exposition in the derivations below, we shall treat the VAR as including only $y$ and $m$. It is straightforward to generalize our results to higher order systems. ${ }^{12}$

Estimates of each subsample VAR produce a set of impulse-response functions similar to those in expressions (18) and (19), namely,

\footnotetext{
12 Although the notation is meant to suggest output and money as the variables, in Section $\mathrm{V}, y$ shall correspond to employment and $m$ to the federal funds rate.
} 


$$
\begin{aligned}
& y_{t}=C_{y m}^{h}(L) \varepsilon_{m t}+C_{y y}^{h}(L) \varepsilon_{y t} \\
& m_{t}=C_{m m}^{h}(L) \varepsilon_{m t}+C_{m y}^{h}(L) \varepsilon_{y t}
\end{aligned}
$$

and consequently $H+1$ sets of conditions similar to those in expression (26). To solve for the parameters of interest $\lambda, a_{k}$ and $b_{i k}$ for $k=0,1, \ldots, K$, consider solving the system of $K \times 2$ equations implied by our subsample estimates. In particular, define $C_{y}=\left[C_{y m 0}, \ldots, C_{y m K}, C_{y y 0}, \ldots, C_{y y K}\right]^{\prime}$, where

$$
\underset{(H+1) \times 1}{C_{y m k}}=\left[\begin{array}{c}
c_{y m k}^{1} \\
\vdots \\
c_{y m k}^{H+1}
\end{array}\right] ; \quad \underset{(H+1) \times 1}{C_{y y k}}=\left[\begin{array}{c}
c_{y y k}^{1} \\
\vdots \\
c_{y y k}^{H+1}
\end{array}\right] k=0,1, \ldots, K .
$$

That is, the vector $C_{y}$ collects the $H+1$ estimates for each of the $K \times 2$ right-hand side terms in expression (26). Similarly, define

$$
\begin{aligned}
& \underset{(H+1) \times(K+2)}{\boldsymbol{X}_{k}}=\left[\begin{array}{ccccccc}
c_{m m 0}^{1} & \ldots & c_{m m k}^{1} & 0 & \ldots & 0 & 1 \\
\ldots & \ldots & \ldots & \ldots & \ldots & \ldots & \ldots \\
c_{m m 0}^{H+1} & \ldots & c_{m m k}^{H+1} & 0 & \ldots & 0 & 1
\end{array}\right] \\
& \underset{(H+1) \times(K+2)}{\boldsymbol{Z}_{k}}=\left[\begin{array}{ccccccc}
c_{m y 0}^{1} & \ldots & c_{m y k}^{1} & 0 & \ldots & 0 & 1 \\
\ldots & \ldots & \ldots & \ldots & \ldots-k & \ldots & \ldots \\
c_{m y 0}^{H+1} & \ldots & c_{m y k}^{H+1} & 0 & \ldots & 0 & 1
\end{array}\right] \\
& k=0,1, \ldots K
\end{aligned}
$$

with

$$
\boldsymbol{W}=\left[\begin{array}{cccccc}
X_{0} & \ldots & 0 & 0 & \ldots & 0 \\
\ldots & \ldots & \ldots & 0 & \ldots & 0 \\
0 & \ldots & X_{K} & 0 & \ldots & 0 \\
0 & \ldots & 0 & Z_{0} & \ldots & 0 \\
0 & \ldots & 0 & \ldots & \ldots & \ldots \\
0 & \ldots & 0 & 0 & \ldots & Z_{K}
\end{array}\right]
$$

Rewriting expression (26) in terms of the auxiliary definitions (28) through (30) we have,

$$
C_{y}=\boldsymbol{W} \boldsymbol{\beta}+\boldsymbol{v} .
$$

Equation (31) represents a system of $K \times 2$ equations based on a sample of size $h+1$, where the parameter vector $\boldsymbol{\beta}^{\prime}=\left[\beta_{1}, \ldots, \beta_{K}, \ldots, \beta_{K \times 2}\right]$ contains a high number of cross-equation restrictions implied by the relations in equation (26) and where $\boldsymbol{v}$ represents the vector of computational error terms for a given $\boldsymbol{\beta}$. For example, the subvectors $\beta_{k}{ }^{\prime}=\left[a_{k}, \lambda a_{k-1}, \ldots\right.$, $\left.\lambda a_{0}, 0, \ldots, 0\right]$ for $k=1, \ldots, K$, and $\beta_{k}{ }^{\prime}=\left[\lambda a_{k}, \lambda a_{k-1}, \ldots\right.$, $\left.\lambda a_{0}, 0, \ldots, b_{k y}\right]$ for $k=K+1, \ldots, K \times 2$. In order to calculate the $\boldsymbol{\beta}$ that satisfies equation (31), one would want to minimize the terms in $\boldsymbol{v}$ with some sensible loss function. A natural candidate is the minimized sum of the squared deviations, which converts the problem of calculating the parameters $\beta$ in equation (31) into one of estimating a panel of $K \times 2$ equations over $H+1$ periods with cross-equation restrictions.

To summarize our empirical strategy: first, locate the structural breaks in the monetary-policy equation; second, estimate a structural VAR for each subsample; third, use these VARs to retrieve the coefficients of the moving-average representations of the VARs (equation (27)); fourth, use these in equation (31) to estimate jointly the $a_{k} s, b_{i k} s$ and $\lambda$ (explicit in equation (26)); finally, having recovered an identified structural model from the unidentified structural VAR, we are in a position to conduct quantified policy analysis.

\section{RECOVERY OF THE STRUCTURAL MODEL}

\section{The Structural VAR}

We draw on the extensive literature on the analysis of monetary policy using linear VARs. We considered specifications based on monthly data that would afford a sufficiently large sample. Even though we believe that there are serious questions about the cogency of the arguments used to justify the identification of the causal ordering of the structural VAR and the typical, albeit not universal, assumption of a Choleski factorization, we want a specification with an established tradition in the literature to avoid lengthy discussions regarding variable choice and structural identification assumptions, which would distract the reader from the main focus of this paper. We hope to revisit this issue in later work. From the available alternatives, we chose the system originally proposed in Christiano, Eichenbaum, and Evans (1996) and slightly modified and used inter alia by Evans and Marshall (1998) and Hamilton and Jordá (2000). ${ }^{13}$

\footnotetext{
${ }^{13}$ The slight modifications consist of using log employment rather than log real GDP, log personal-consumption-expenditure deflator rather than log GDP price deflator, and the ratio of nonborrowed reserves to total reserves rather than log nonborrowed reserves.
} 
Our data sample runs from January 1960 to January 1999. The data vector is given by $S=[E M$, $P, P C O M, F F, N B R X, \triangle M 2]^{\prime}$, where EM denotes the logarithm of nonagricultural payroll employment; $P$ denotes the logarithm of the personal consumption expenditures deflator $(1996=100) ; P C O M$ denotes the annual growth rate of the index of sensitive materials prices issued by the Conference Board; FF denotes the federal funds rate; $N B R X$ denotes the ratio of nonborrowed reserves plus extended credit to total reserves; and $\triangle M 2$ denotes the annual growth rate of the monetary aggregate M2. Data are seasonally adjusted. All logged data are multiplied by 100 so that impulse responses can be interpreted directly as percent deviations. The inclusion of the variable PCOM has now become customary in monetary VARs to mitigate the anomalous responses of the price-level to monetary-policy shocks (the so-called "price puzzle" described in Sims, 1992, and Eichenbaum, 1992). The contemporaneous variables are causally ordered through a Choleski factorization in which the Wold causal order is the order in which the variables are written in the vector $S$. To conserve parsimony and degrees of freedom, we experimented with several lag length specifications. A lag length of 4 seemed adequate (for example, the Durbin-Watson statistic for the $F F$ equation had a value of 2.0267) to capture the dynamic properties of our problem.

\section{Monetary Policy Regimes}

In the analysis that follows, employment (EM) will be regarded as the real output measure ( $y$ in our theoretical exposition) and the federal funds rate $(F F)$ as our monetary-policy instrument ( $m$ in the theoretical exposition).

The first task required by our methodology is to identify dates of monetary policy regime shifts. Detailed institutional accounts can be found inter alia in Meulendyke (1998) and Strongin (1995). That the period from October 1979 to October 1982 is a monetary-policy regime distinct from what came before or after is, perhaps, the most commonly agreed fact about monetary policy regimes in the United States. This regime targeted nonborrowed reserves, while the immediately preceding and following regimes essentially targeted interest rates. The dates October 1979 to October 1982 are frequently identified by purely statistical methods as structural breaks in short-term nominal interest rates (see, for example, Garcia and Perron, 1996, and the references therein). There is, however, consider- ably less agreement with regard to the dates of other regimes.

We rely on a combination of institutional knowledge and the sup $F$ tests for structural breaks at unknown dates due to Bai and Perron (1998). ${ }^{14}$ These tests are a generalization of the well-known test of Andrews (1993). In particular, we test the policy-reaction equation of the VAR described in the previous section in its structural form, namely,

$$
F F_{t}=\boldsymbol{\Gamma}_{t}^{\prime} \boldsymbol{\beta}_{h}+u_{t} \quad h=1, \ldots, H+1,
$$

where $\Gamma_{t}^{\prime}$ includes a constant; up to four lags of the vector $S$ described in the previous subsection, and the contemporaneous values of $E M, P, P C O M$. The index $h$ refers to the number of breaks which delivers $H+1$ possible regimes. We allow for the possibility that all of the coefficients, and not just the intercept, may change.

The first stage of the test requires that we calculate the unknown break dates $T_{h}, h=1, \ldots, H$ along with the unknown coefficients $\boldsymbol{\beta}_{h}$. The method suggested by Bai and Perron (1998) requires that we specify a maximum number of possible break points (which we set at eight, corresponding to at most nine distinct regimes) as well as a minimum size partition $\tau$ such that $T_{h}-T_{h-1}>\tau T$. We choose $\tau=10$ percent, constraining the minimum subsample size to 46 observations (this choice afforded a reasonable number of degrees of freedom for estimation of equation (32)).

It is important to highlight this particular feature because it conditions the candidate dates for possible breaks. In particular, the beginning and end of the nonborrowed-reserves targeting regime (October 1979 to October 1982) are separated by fewer than 46 observations, and, therefore, the regime does not afford the minimum number of observations needed for computation. As we shall see, however, this did not constitute a significant impediment. The test detected breaks at June 1978 and at April 1982, which are separated by exactly the minimum 46 observations and bracket a period that includes nearly all of the nonborrowed-reserves targeting period.

The method of estimation is based on the least-squares principle. For each $h$ partition $\left(T_{1}, \ldots\right.$, $T_{H}$ ), the associated least-squares estimates for $\boldsymbol{\beta}_{h}$ are obtained by minimizing the sum of squared residuals

\footnotetext{
${ }^{14}$ We thank Jushan Bai for generously providing us with the code used in this paper to run the structural break tests.
} 


\section{Table 2}

\section{Structural Break Tests of the Monetary-Policy Equation}

\begin{tabular}{|c|c|c|c|c|c|c|c|c|}
\hline $\begin{array}{c}\text { Number of break } \\
\text { under the } \\
\text { alternative, } \boldsymbol{H}\end{array}$ & $\sup F(H \mid 0)$ & & $\begin{array}{c}5 \% \\
\text { Critical value }\end{array}$ & $\sup F(H+1 \mid H)$ & $\begin{array}{c}5 \% \\
\text { Critical value } \\
\end{array}$ & & AIC & BIC \\
\hline 1 & 106.59 & & 64.69 & - & - & & 0.2320 & 0.3027 \\
\hline 2 & 125.92 & & 58.56 & 119.92 & 68.12 & & 0.1318 & 0.2244 \\
\hline 3 & 117.20 & & 55.52 & 96.80 & 70.21 & & 0.1254 & 0.2785 \\
\hline 4 & 106.32 & & 53.16 & 96.80 & 71.09 & & 0.1222 & 0.3540 \\
\hline 5 & 123.22 & & 50.93 & 90.20 & 71.84 & & 0.1178 & 0.4452 \\
\hline 6 & 124.74 & & 48.77 & 70.62 & 72.59 & & 0.1193 & 0.5882 \\
\hline 7 & 102.92 & & 46.29 & 46.76 & 73.83 & & 0.1267 & 0.8151 \\
\hline 8 & 88.84 & & 42.83 & 52.22 & 74.83 & & 0.1395 & 1.1707 \\
\hline Breaks & \multicolumn{8}{|c|}{ Dates } \\
\hline 1 & & & & 1980:6 & & & & \\
\hline 2 & & & & 1978:6 & 1982:4 & & & \\
\hline 3 & & 1970:4 & & 1978:6 & 1982:4 & & & \\
\hline 4 & & 1970:4 & & 1978:6 & 1982:4 & 1986:2 & & \\
\hline 5 & & 1970:6 & 1974:6 & 1978:6 & 1982:4 & 1986:2 & & \\
\hline 6 & 1965:5 & 1970:9 & 1974:5 & 1978:6 & 1982:4 & 1986:2 & & \\
\hline 7 & 1965:5 & $1970: 9$ & 1974:5 & 1978:6 & 1982:4 & 1986:2 & & \\
\hline 8 & $1965: 5$ & 1970:9 & 1974:5 & 1978:6 & 1982:4 & 1986:2 & 1989:12 & 1994:8 \\
\hline
\end{tabular}

NOTE: The 5 percent critical values are extrapolated from Bai and Perron (1998, Table I).

$$
\sum_{h=1}^{H+1} \sum_{t=T_{h-1}+1}^{T_{h}}\left[F F_{t}-\boldsymbol{\Gamma}_{t}^{\prime} \boldsymbol{\beta}_{h}\right]^{2}
$$

Denote the resulting sum of squared residuals $S_{T}\left(T_{1}, \ldots, T_{H}\right)$, and the estimated break points $\hat{T}_{1}, \ldots$, $\hat{T}_{H}$ are such that

$$
\hat{T}_{1}, \ldots, \hat{T}_{H}=\operatorname{argmin}_{T_{1}, \ldots, T_{H}} S_{T}\left(T_{1}, \ldots, T_{H}\right),
$$

where the minimization is taken over all partitions $\left(T_{1}, \ldots, T_{H}\right)$ such that $T_{h}-T_{h-1}>\tau T .{ }^{15}$

Once the break dates have been estimated for the different values of $H$, we apply the sup $F$ test of the null of no structural breaks $(H=0)$ versus the alternative hypothesis that there are $H$ (for $H=1$, $2, \ldots, 8)$ breaks as well as the $\sup F$ of the null that there are $H+1$ structural breaks versus the alternative of $H$ breaks. The $F$ test consists essentially of the appropriately normalized ratio of the sum of squared residuals under the null to the sum of squared residuals under the alternative hypothe- sis. ${ }^{16}$ The tests are flexible enough that they permit lagged dependent variables as regressors as long as the residuals are serially uncorrelated. ${ }^{17}$ Table 2 summarizes the results of the test. The tests suggest that the null hypothesis is strongly rejected for all values of $H$, although the maximum value of sup $F(H \mid 0)$ is attained for $H=2(125.92)$ with $H=5,6$ in close proximity (123.22 and 124.74 , respectively). The sup $F(H+1 \mid H)$ indicates that for $H<6$, the null hypothesis is easily rejected, indicating that a value of $H=5$ would be appropriate. These results seem to be confirmed by the information criteria: Akaike information criterion (AIC) selects a more generous specification with five breaks, whereas Bayesian

\footnotetext{
${ }^{15}$ The algorithm used to compute expression (16) is discussed in Bai and Perron (1996).

16

The specific form of these tests is described in Bai and Perron (1998, Section 4).

${ }^{17}$ Recall the Durbin-Watson statistic for the $F F$ equation is 2.0267 .
} 
information criterion (BIC) would suggest a more conservative specification with two breaks. We choose $H=5$ because, for the purposes of our exercise, there is no bias in having redundant regimes (although there may be some loss of efficiency in the estimates of the impulse responses). The estimated break dates match relatively well with institutional developments at the Federal Reserve, even for values of $h$ that are larger than our final selection. For instance, in 1970 the Federal Reserve revised its Regulation $\mathrm{Q}$ to eliminate interest-rate ceilings on bank certificates of deposit, and it formally adopted monetary targets with the intention to reduce inflation. Further developments in 1972 included the introduction of new required-reserve ratios and the introduction of targets for the growth of money over a 6-month horizon. We have already commented on the nonborrowed-reserves targeting regime spanning October 1979 to October 1982, which loosely coincides with the June 1978 to April 1982 break dates detected. The February 1986 date can be associated with the end of Volcker's chairmanship. Other dates that were not selected but related to institutional changes at the Fed include the beginning of free reserves targeting in 1966, which corresponds well to the detected May 1965 break date. The December 1989 break date coincides with the "Thanksgiving 1989 effect" described in Hamilton and Jordá (2000) and Demiralp and Jordá (2000). The August 1994 break date can be tied to the practice, instituted by the Fed in February of that year, of publicly announcing changes in the federal funds rate target after FOMC meetings.

At this juncture, we considered two alternatives. The dates detected by the structural break tests can be connected broadly to conventional monetary-regime shifts for which we have relatively accurate documented shift-dates. In the end, however, rather than imposing our own priors, we decided to maintain the break dates detected by Bai and Perron's (1998) test for $H=5$ under the view that, in practical terms, these well-known shifts may have exerted their true effects with some lead or lag.

\section{Estimating $\lambda$}

Once we have determined the dates of monetary regime shifts, it is straightforward to compute the impulse responses of $E M$ to shocks in $F F$ (that is, $y_{t}$ and $m_{t}$ in the notation of previous sections) as well as shocks in $P, P C O M, N B R X$, and $\triangle M 2$ for each of the $H+1$ subsamples determined by the breaks in
Table 2. Each subsample VAR has the same structure. For each subsample we compute a set of impulse-response functions such as those described in expression (27), which we then used to set up the system described by equations (29) to (31).

Estimation of this system yields an estimate of $\lambda=0.57$ with a standard error of $0.14 .^{18}$ The estimate of $\lambda$ provides a direct measure of the existence of the Lucas critique. The fact that we find breaks in the monetary policy rule confirms the results of Estrella and Fuhrer (1999). Yet to underwrite their conclusion that the Lucas critique is not quantitatively relevant, we would also have to have found that $\lambda=1$. Instead, we found a value rather closer to the value for the mixing parameter between permanent-income and rule-of-thumb consumers in Campbell and Mankiw's (1989) test of the consumption function.

To understand what the estimate of $\lambda=0.57$ means consider Figure 1. ${ }^{19}$ The top panel shows the output effect of an unanticipated impulse to $F F$ on $E M$ for three values of $\lambda$. An unanticipated impulse occurs when the monetary surprise term in square brackets in the middle term on the righthand side of equation (17) takes a non-zero value. Figure 1 plots the coefficients of the polynomial $A(L)$ that provide the dynamic response to that shock. ${ }^{20}$ The lower curve (solid line) shows the function for the Lucasian case, $\lambda=0$. Except for the scale factor $\left(c_{m m 0}\right)$ this is the ordinary impulse response function for the structural VAR (see equation (20)). The upper curve (gray line) shows the function for the rule-of-thumb case, $\lambda=1$. The quantitative responses are much more moderated in this case since systematic monetary policy acts to offset the monetary surprise. Finally, the middle curve (dotted line) shows the intermediate case in which the mixing parameter takes the estimated value, $\lambda=0.57$. Although this value is near to the midpoint of the range of possible values for $\lambda$, the quantitative

\footnotetext{
${ }^{18}$ Caution should be used in interpreting this standard error. Note that the regressors of the system used to estimate $\lambda$ have been generated from the subsample VARs, and therefore their sampling variation should be incorporated when evaluating the precision of the estimated $\lambda$.

${ }^{19}$ This figure is the analogue of Cochrane's Figure 6 (1998, p. 294). Our real variable is employment; his is output.

${ }^{20}$ It is worth recalling that one of our identifying assumptions $A(L)$ is constant for a given $\lambda$ whatever the monetary regime, but that, in general, $A(L)$ will be different for different $\lambda$ 's. Because the coefficients of the monetary policy rule do not enter into the dynamics reported here, Figure 1 is the same for all regimes.
} 
responses are much closer to the rule-of-thumb case than to the Lucasian case, which corresponds closely to Cochrane's (1998) conclusion that the economy acted more like an economy with no rational agents when even a relative few followed a rule of thumb.

The lower panel of Figure 1 shows the output responses of $E M$ to an anticipated impulse to $F F$ for the three values of $\lambda$. It shows the direct effect only - that is, it corresponds to the first term on the right-hand side of equation (17) rather than to the impulse-response function (calculated from equation (20)) that incorporates the indirect feedback of monetary policy on EM. Each curve in the lower panel is a scaling of the corresponding curve in the upper panel by the appropriate value of $\lambda$. When $\lambda=0$ (straight line), there is no response at all: in the Lucasian world only monetary surprises have real effects. When $\lambda=1$ (gray line), the curve is the same as the corresponding curve in the upper panel. The two messages of the panel are as follows: first, except in the Lucasian case, anticipated policy has real effects; and, second, the direct effects of anticipated policy are uniformly more moderate than had the same policy action been unanticipated.

\section{EVALUATING SYSTEMATIC MONETARY POLICY}

With estimates of equation (16) in hand, we are now in a position to quantify the effects of systematic monetary policy. We do this in three ways: first, we present a decomposition of the effects of monetary policy into systematic and unsystematic responses to shocks to monetary policy and to shocks to employment; second, we compare the estimated systematic impulse-response functions from our identified structural macroeconometric model to the counterfactual experiments that Sims and Zha (1998) suggest as measures of systematic policy; and, finally, we consider counterfactual simulations of the structural macroeconometric model in the spirit of Sims's (1999) counterfactual simulations.

\section{The Systematic Monetary-Policy Component of Impulse-Response Functions}

For each policy regime, the top panel of Figure 2 plots $\lambda A(L) C_{m m}$, which according to equation (20) is the systematic component of the impulse-response function for $E M$ to a 1 percent positive shock to the

\section{Figure 1}

Response of Employment to the Components of a Monetary Shock
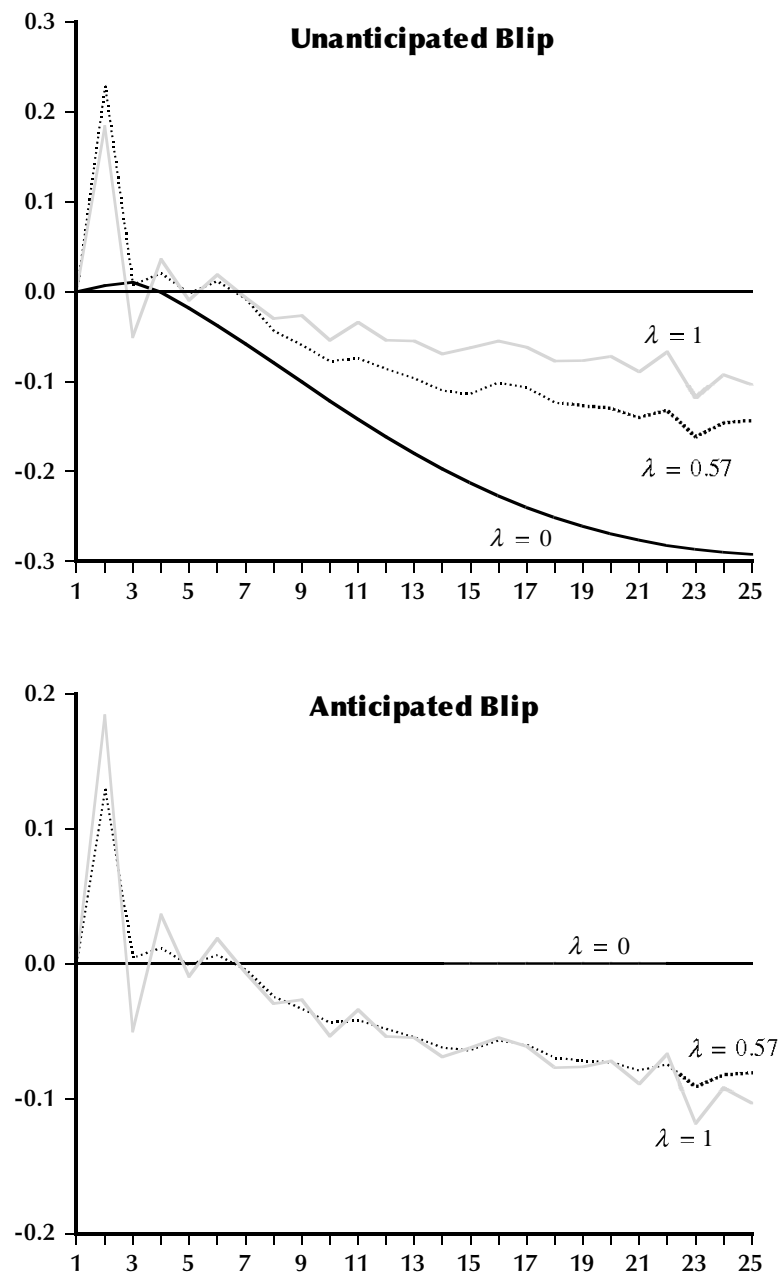

NOTE: This decomposition mirrors that in Cochrane (1998, page 294, Figure 6).

federal funds rate $\left(\varepsilon_{m t}\right)$. Similarly, the bottom panel plots $\lambda A(L) C_{m y}$, which is the systematic component of the impulse-response function of $E M$ to a 1 percent negative shock EM itself $\left(\varepsilon_{y t}\right)$.

An unanticipated positive shock to the federal funds rate can be regarded as inadvertent tightening. The top panel of Figure 2 shows that in every regime the initial effect is to lower employment. In all but the 1974-78 regime, monetary policy sustains that tightening for some time, although in three of the regimes it is neutralized or reversed within two years. However, for the 1960-70 regime, policy follows a pattern of sustained tightening so that 
Figure 2

\section{The Effects of Systematic Monetary Policy Across Regimes}
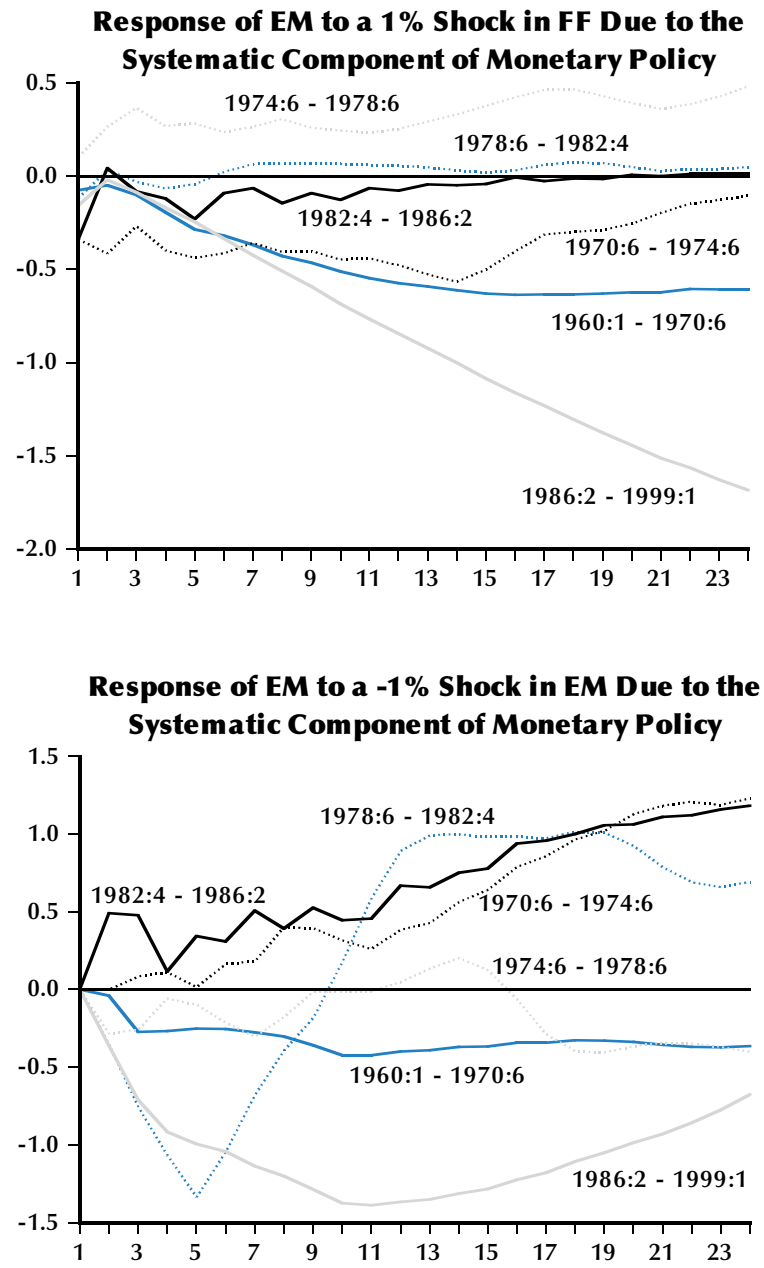

employment is 0.5 percent lower after two years. A similar, but more substantial tightening occurs in the 1986-99 regime: a nearly 2 percent fall after two years.

The lower-panel is perhaps more interesting for policy as it shows the systematic monetary response to an unanticipated real development. A fall in employment is a surprise cooling of the economy. In two of the regimes (1970-74 and 1982-86), policy more than reverses the shock - reaching a 1 percent increase at the end of two years. In two of the regimes (1960-70 and 1986-91) policy accelerates the drop in employment-reaching around 0.5 percent further reduction after two years. In the remaining two regimes, the behavior is mixed. In both the 1974-76 and 1978-82 regime, the initial effect is to further reduce employment. In the 1974-78 regime the employment shock is neutralized by nine months and reversed by one year. Still, by the end of two years the net effect is about 0.5 percent further reduction. In the 1978-82 regime, there is a similar reversal by nine months, but at the end of two years employment has been raised by 0.5 percent. The behavior of the Federal Reserve does not correspond in any regime exactly to William McChesney Martin's description of the Fed as taking away the punch bowl just as the party is getting started. Faced with a dull party, the Fed, in three of the regimes, spikes the punch and, in the other three, laces it with poison. In every regime, systematic monetary policy is important.

\section{A Comparison with Sims and Zha's Counterfactual Experiment}

A number of recent papers employ counterfactual methodologies to assess the effects of systematic monetary policy. Sims and Zha (1998) modify the equation that they identify as the policyreaction function while maintaining the rest of the equations in a structural VAR unchanged. The authors concede that this would be an objectionable procedure, given the Lucas critique, since it ignores the endogenous response of the public to the new policy regime. They argue, however, that the public would require time to learn about the new policy regime, so that the Lucas critique is unlikely to be operative over a relatively short forecast horizon. Bernanke, Gertler, and Watson (1997) refine this defense of the counterfactual procedure with the argument that the Lucas critique is more important for some markets than for others. Their counterfactual experiments are similar to those of Sims and Zha.

In practice, Sims and Zha's procedure is to replace the equation for the federal funds rate in the structural VAR with a constant. This amounts to a firmly maintained target for the federal funds rate. The rationale for ignoring the Lucas critique in this case is equivalent to the assumption that $\lambda=1$, at least over the horizon of interest to the policymaker. Yet, there is an inconsistency since, as we demonstrated in Section IV, using the usual structural VAR to assess the effect of monetary policy is equivalent to assuming that $\lambda=0$. In any case, the evidence of this paper is that $\lambda$ is neither 1 nor 0 . The Lucas critique cannot be completely 
ignored, although as Figure 1 suggests it may not be quantitatively as important as when all agents have rational expectations. But neither should we assume that the economy is affected only by surprises in the monetary instrument that have real effects as the usual impulse-response functions imply.

Our argument is that the attempt to isolate the systematic effects of monetary policy through the sort of counterfactual experiment suggested by Sims and Zha (1998) is likely to be misleading. How misleading can be seen in Figure 3 in which we compare estimates for each policy regime of an impulseresponse function for a negative 1 percent shock to $E M$ using their methodology to calculate the systematic effect of monetary policy on $E M$ reported previously in Figure 2. In every case, our estimates of the systematic effects of monetary policy are smaller in absolute value - typically period-byperiod and always by the end of two years - than those of Sims and Zha. For the 1978-82 regime, even though the two estimates end up at nearly the same value, the paths are nearly mirror images of each other. For the 1986-99 regime, Sims and Zha's method suggests that a negative employment shock is met with an increasingly large, systematically countervailing policy response. In contrast, our estimates suggest a small response ratifying the shock in the midterm but offsetting it almost completely by the end of two years.

\section{A Counterfactual Simulation}

Sims (1999) conducts a counterfactual experiment in which he takes the monetary policy equation from the postwar periods and inserts it into a structural VAR for the prewar period. He then feeds the actual shocks from the prewar VAR into the new "chimera" with the intent of seeing how the economy would have fared during the Great Depression had it had the postwar monetary policy in placewould the modern Fed have done better than the Fed in fact did in the period between the two World Wars? This counterfactual is open to the same objection that we raised against Sims and Zha's other counterfactual experiment: it is an inadequate and inconsistent response to the Lucas critique. One problem is that the "structural" VAR is not structural enough to sustain the counterfactual experiment in the face of the evidence that the Lucas critique is in fact operative to some degree. And, as before, the usual impulse-response function makes sense only in the surprise-only Lucasian economy of $\lambda=0$.
In contrast, to the degree that our identifying assumptions are correct, we can perform a legitimate counterfactual experiment. Like Sims, we consider a turbulent time, but one closer to our own time-the period at the end of the 1970s through the double-dip recessions of the early 1980s. This is the period of the Federal Reserve's nonborrowedreserves operating regime. Our counterfactual experiment uses the shocks from the period 1978:7 to $1982: 4$, which is the period indicated by our break tests that essentially overlaps the period of recessions and volatile interest rates. We refer to this period as "Volcker (actual)," designating it by the Federal Reserve chairman in office through most of it. The shocks and appropriate initial conditions are fed into the structural macroeconometric models identified for the regimes 1974:6 to 1978:6 ("BurnsMiller") and 1986:2 to 1999:1 ("Greenspan")-each also designated by the corresponding Chairman of the Federal Reserve. ${ }^{21}$

The results of the counterfactual experiment presented in Figure 4 are interesting-if not completely intuitive. The shaded area displayed on the six panels in Figure 4 corresponds to the July 1980July 1981 recession and the original variables of the VAR are appropriately transformed to be more readily interpretable. ${ }^{22}$ At the start of the recession, the decline in employment growth is similar under the stewardships of Greenspan and Volcker (somewhat more dramatic under the Burns-Miller scenario). However, the decline in the real federal funds rate a couple of periods into the recession is more dramatic under Volcker's chairmanship than it is under Greenspan's. This has the effect of reducing the fall in employment growth much more quickly, with employment growth attaining positive values eight months into the recession. By contrast, the real federal funds rate declines much less markedly under Greenspan (the trough of this decline is eight months into the recession) and Burns-Miller (the trough is reached five months

\footnotetext{
${ }^{21}$ Recall that to identify the structural macroeconometric model, $A(L)$ and $B(L)$ (and, of course, $\lambda$ ) are assumed to be constant across regimes. Feeding the shocks from one regime in the model for another amounts, then, only to changing the monetary rule. This is a little different from Sims's (1999) experiment. Sims assumes that the prewar and postwar periods are characterized by different real structures as well as different monetary rules.

22 The annual growth rates of employment, M2, and the nonborrowed reserve ratio as well as inflation, and inflation in sensitive commodities, are calculated as the 12th difference of the logarithms of the levels. The real federal funds rate is calculated as the nominal rate minus the inflation rate.
} 


\section{Figure 3}

The Monetary Amplification/Mitigation of a -1\% EM to Employment:

A Comparison Between Sims and Zha, and Cochrane's Decompositions
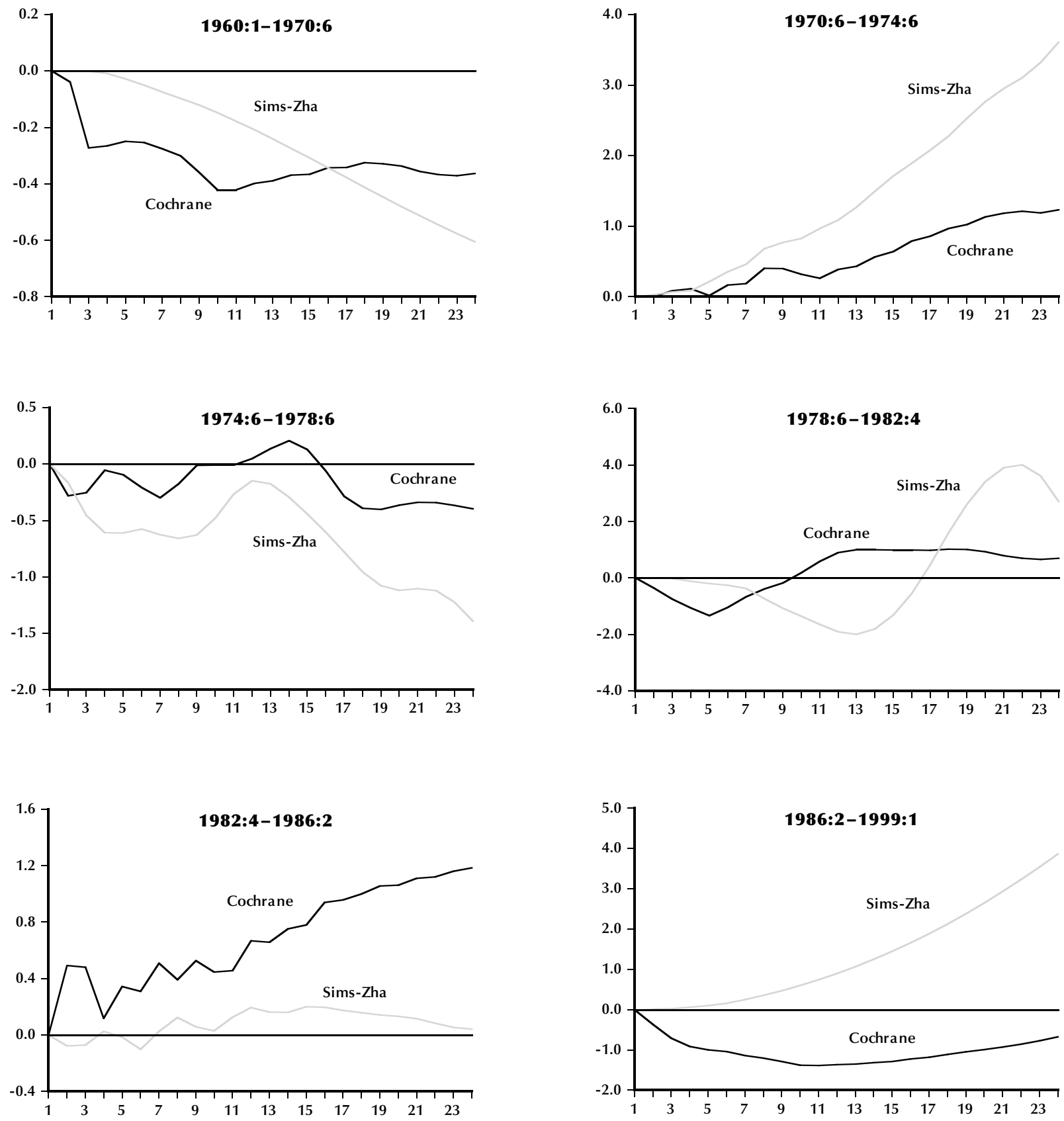

NOTE: Cochrane denotes the difference between the traditional impulse response function from the VAR and the orthogonal component of the response to monetary policy obtained on the basis of equation (22). Sims and Zha denote the difference between the traditional impulse response function from the VAR and the response one would obtain if the funds variable is maintained at a constant level throughout. 


\section{Figure 4}

Counterfactual Simulations

Fed Chairmen Performance During the 1979:7- 1982:4 Period
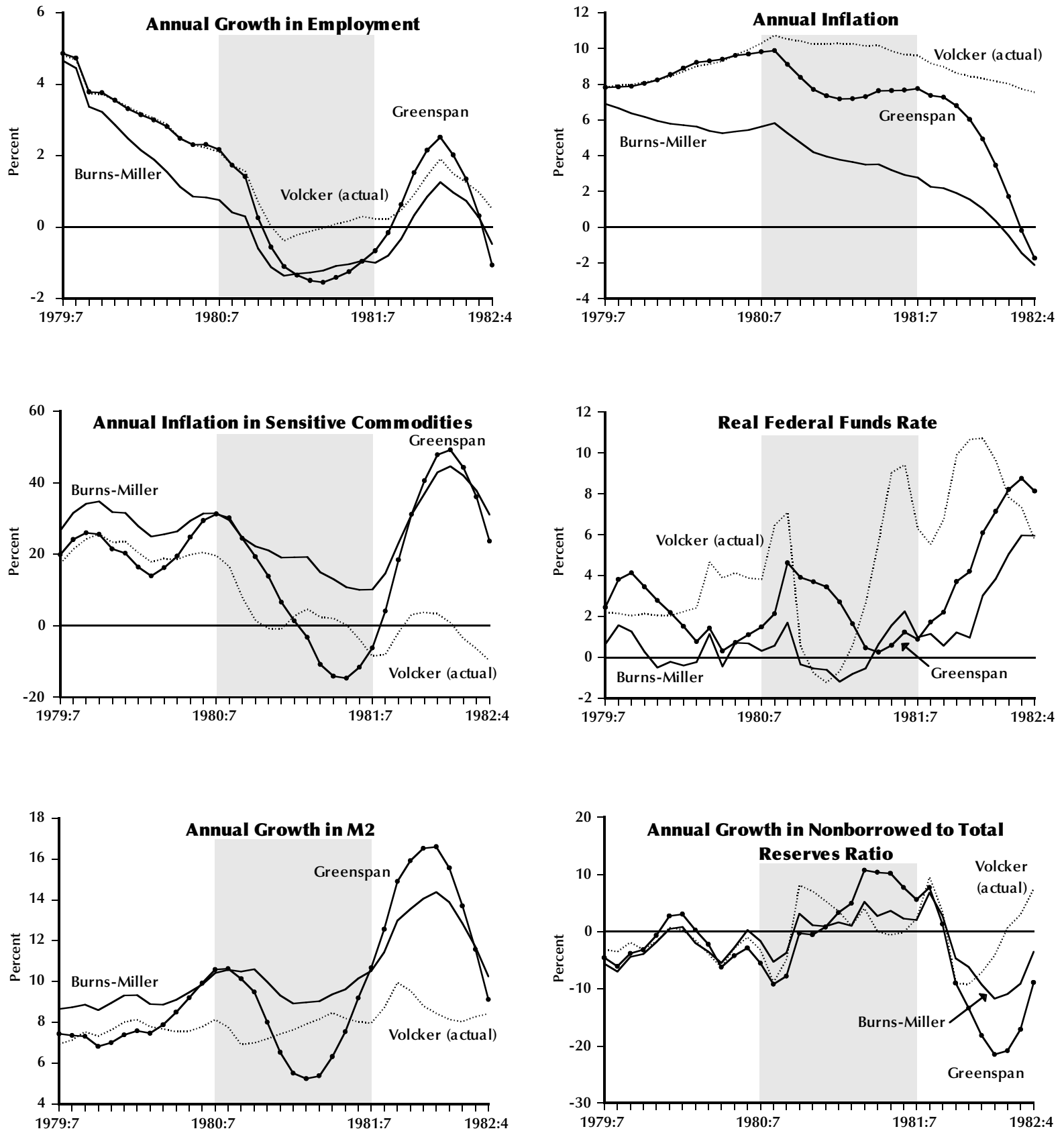

NOTE: The simulations replace the FF equation of the VAR estimated over the 1978:7-1982:4 period (Volcker chairmanship), the 1974:6-1978:6 period (Burns-Miller chairmanship), and the 1986:2-1999:1 period (Greenspan chairmanship). Shaded area depicts the July $1980-J u l y ~ 1981$ recession. 
into the recession instead) and over a longer period of time. This causes a deeper and more protracted decline in employment growth, and a subsequent longer recovery relative to Volcker. Upon exiting the recession, both Greenspan and Burns-Miller aggressively ratchet up the federal funds rate but with an eight month lag relative to Volcker's actions.

The policies of both Greenspan and Burns-Miller would have held the federal funds rate at a substantially lower level than was actually the case under Volcker. More important, perhaps, is that both Greenspan and Burns-Miller would have delivered a much less volatile federal funds rate during the recession than Volcker actually did. As a result, they would have had substantially more difficulty in hitting the M2 monetary targets that were one of the guides to monetary policy at the time, even though there are few appreciable differences in the behavior of the ratio of nonborrowed reserves to total reserves.

Perhaps the most unintuitive result of this experiment has to do with the behavior of inflation and inflation in sensitive materials. In particular, a rate of inflation for consumer goods higher under Volcker than under the others is consistent with a relatively quicker recovery from the recessions. What is puzzling is why the rate of inflation for sensitive materials should remain low under the Volcker regime but not under the others while general inflation accelerated.

The real outcomes are mildly surprising since Paul Volcker was widely regarded as running a tighter monetary policy than had his predecessors, Arthur Burns and William Miller. The Volcker regime exhibits greater employment than would have been the case under either the Burns-Miller or the Greenspan regimes. The correlative consequences for inflation-consistent with the Phillips curvewould have been lower prices in the two regimes with lower employment and indeed would have turned into disinflation by the end of the period.

The difference between the configurations of employment, inflation, and interest rates produced by Volcker's policy compared with the alternatives is consistent with the Federal Reserve having adjusted the federal funds rate in a manner that adapted to the higher inflation - in effect building higher expectations of inflation into policy. What remains difficult to understand, however, is why the prices of sensitive commodities would rise substantially under the apparently tighter regimes of Greenspan and Burns-Miller.

\section{CONCLUSION}

Our goal was not only to understand the nature and significance of systematic monetary policy but also to make some sense of the voluminous literature based in structural VARs. The great tension in the empirical analysis of monetary policy is between the need for a structural account that can support the kind of counterfactual analysis needed for policy analysis and the need for modesty on the part of macroeconometricians in their claims for empirical warrant (or even credibility) for the assumptions used to identify that structure. Lucas's original program set a high standard for the requisite structural detail. Sims's original VAR program advised a high degree of modesty. Macroeconomics has tried to steer between their competing claims ever since. Cochrane (1998) was a warning to the structural VAR camp to steer toward the Lucas light. What we hope to have achieved in this paper is to demonstrate that there is deeper water in that direction.

The results of this study are preliminary. We have followed other recent studies in adopting a particular contemporaneous causal ordering of the structural VAR. But this is a highly contested area. Different causal structures could significantly affect our results. Similarly, there remain questions about the identification of monetary policy regimes. And there are questions not really addressed here at all of how to characterize monetary policy. We assumed that the federal funds rate was the policy instrument. It would be worth exploring whether a larger block of monetary-policy variables could be analyzed in a similar manner. Finally, there are, of course, many counterfactual experiments that we could address beyond the particular case of the early 1980s. What we have accomplished-even in this preliminary form - is to show that there is an empirically workable template on which a more refined and comprehensive study can be based.

Although preliminary, our results are interesting. First, the economy is best characterized as being composed of a mixture of agents, some of whom operate according to the new classical paradigm (rational expectations, short-run neutrality of money) and some of whom appear to follow rules of thumb. The estimate of $\lambda=0.57$ could be read as saying Lucas was 43 percent right in his early newclassical model of the macroeconomy. Second, even with only half the economy in the rule-of-thumb camp, the economy behaves quantitatively and qualitatively substantially as if Lucas had been 
wrong altogether about the unimportance of systematic and anticipated monetary policies. Third, Lucas is correct, nonetheless, that the aggregate reactions of the economy are conditioned on policy regimes and the analysis of what happens when a regime changes-in practice as well as in theory-requires some structural knowledge. The key assumption of this paper is that the coarse structural knowledge suggested in Cochrane's decomposition of the effects of monetary policy into anticipated and unanticipated components is sufficient-and very likely the best that we can practically accomplishto reach substantive results.

\section{REFERENCES}

Andrews, Donald W.K. "Tests for Parameter Instability and Structural Change with Unknown Change Point." Econometrica, July 1993, 61(4), pp. 821-56.

Bai, Jushan and Perron, Pierre. "Computation and Analysis of Multiple Structural Change Models.” Working Paper, Université de Montréal, 1996.

and "Estimating and Testing

Linear Models with Multiple Structural Changes." Econometrica, January 1998, 66(1), pp. 47-78.

Barro, Robert J. "Unanticipated Money Growth and Unemployment in the United States." American Economic Review, March 1977, 67(2), pp. 101-15.

"Unanticipated Money, Output, and the Price Level in the United States." Journal of Political Economy, 1978, 86(4), pp. 549-80.

and Rush, Mark. "Unanticipated Money and Economic Activity," in Stanley Fischer, ed., Rational Expectations and Economic Policy. Chicago: University of Chicago Press, 1980, pp. 22-48, 72-73.

Basmann, R.L. "A Note on the Statistical Testability of 'Explicit Causal Chains' Against the Class of 'Interdependent' Models." Journal of the American Statistical Association, 1965, 60(312), pp. 1080-93.

Bernanke, Ben S.; Gertler, Mark and Watson, Mark. "Systematic Monetary Policy and the Effects of Oil Price Shocks." Brookings Papers on Economic Activity, 1997, (1), pp. $91-142$.

Campbell, John Y. and Mankiw, N. Gregory. "Consumption, Income and Interest Rates: Reinterpreting the Time Series Evidence." NBER Macroeconomics Annual, 1989. Cambridge, MA: MIT Press, 1989, pp. 185-216.
Christiano, Lawrence J.; Eichenbaum, Martin and Evans, Charles L. "Identification and the Effects of Monetary Policy Shocks," in Mario I. Blejer, Zvi Eckstein, Zvi Hercowitz, and Leonardo Leiderman, eds., Financial Factors in Economic Stabilization and Growth. Cambridge: Cambridge University Press, 1996, pp. 36-74.

Cochrane, John H. "What Do the VARs Mean? Measuring the Output Effects of Monetary Policy." Journal of Monetary Economics, April 1998, 41(2), pp. 277-300.

Cooley, Thomas F. and LeRoy, Stephen F. "Atheoretical Macroeconometrics: A Critique." Journal of Monetary Economics, November 1985, 16(3), pp. 283-308. and Raymon, Neil. "Econometric Policy Evaluation: A Note.” American Economic Review, May 1984, 74(2), pp. 467-70.

Demiralp, Selva and Jordá, Oscar. "The Pavlovian Response of Term Rates to Fed Announcements.” Working Paper 99-06R, University of California, Davis, 2000.

Eichenbaum, Martin. "Interpreting the Macroeconomic Time Series Facts: The Effects of Monetary Policy: Comments." European Economic Review, June 1992, 36(5), pp. 1001- 11 .

Estrella, Arturo and Fuhrer, Jeffrey C. "Are 'Deep' Parameters Stable? The Lucas Critique as an Empirical Hypothesis." Working Paper No. 99-4, Federal Reserve Bank of Boston, 1999.

Evans, Charles L. and Marshall, David A. "Monetary Policy and the Term Structure of Nominal Interest Rates: Evidence and Theory." Carnegie-Rochester Conference Series on Public Policy, 1998, 49, pp. 53-111.

Fischer, Stanley. "Long-Term Contracts, Rational Expectations, and the Optimal Money Supply Rule.” Journal of Political Economy, February 1977, 85(1), pp. 191-205.

Fuhrer, Jeff and Moore, George. "Inflation Persistence." Quarterly Journal of Economics, 1995, 110(1), pp. 127-59.

Garcia, Rene and Perron, Pierre. "An Analysis of the Real Interest Rate under Regime Shifts." Review of Economics and Statistics, 1996, 78(1), pp. 111-25.

Gordon, Robert J. "What Is New-Keynesian Economics?" Journal of Economic Literature, 1990, 28(3), pp. 1115-71. 
Haase, Charles W. The Macroeconomic Effects of Rule-ofThumb Consumer Behavior. Ph.D. Dissertation, University of California, Davis, 1998.

Haltiwanger, John C. and Waldman, Michael. "Limited Rationality and Strategic Complements: The Implications for Macroeconomics." Quarterly Journal of Economics, August 1989, 104(3), pp. 463-83.

Hamilton, James and Jordá, Oscar. "A Model for the Federal Funds Rate Target.” Working Paper 7847, National Bureau of Economic Research, August 2000.

Hansen, Lars Peter and Sargent, Thomas J. "Formulating and Estimating Dynamic Linear Rational Expectations Models." Journal of Economic Dynamics and Control, 1980, 2(1), pp. 7-46.

Hartley, James E. The Representative Agent in Macroeconomics, Frontiers of Political Economy. Vol. 10. London: Routledge, 1997.

Hendry, David F. and Morgan, Mary S., eds. The Foundations of Econometric Analysis. Cambridge: Cambridge University Press, 1995.

Hoover, Kevin D. The New Classical Macroeconomics: A Sceptical Inquiry. Oxford: Blackwell, 1988.

The Methodology of Empirical Macroeconomics. Cambridge: Cambridge University Press, 2001a (forthcoming).

. Causality in Macroeconomics. Cambridge:

Cambridge University Press, 2001b (forthcoming).

Kirman, Alan. P. "Whom or What Does the Representative Individual Represent?" Journal of Economic Perspectives, Spring 1992, 6(2), pp. 117-36.

Kydland, Finn E. and Prescott, Edward C. "Time to Build and Aggregate Fluctuations.” Econometrica, 1982, 50(6), pp. 1345-70.

Leamer, Edward E. "Vector Autoregressions for Causal Inference?" Carnegie-Rochester Conference Series on Public Policy, 1985, 22, pp. 255-303.

LeRoy, Stephen F. “On Policy Regimes,” in Kevin D. Hoover, ed., Macroeconometrics: Developments, Tensions and Prospects. Boston: Kluwer, 1995, pp. 235-51.
Lucas, Robert E., Jr. "Expectations and the Neutrality of Money." Journal of Economic Theory, April 1972, 4(2), pp. 103-24.

"Some International Evidence on OutputInflation Tradeoffs." American Economic Review, June 1973, 63(3), pp. 326-34.

"An Equilibrium Model of the Business Cycle.” Journal of Political Economy, December 1975, 83(6), pp. 1113-44.

"Econometric Policy Evaluation: A Critique." Journal of Monetary Economics, Supplementary Series, 1976a, 1(2), pp. 19-46.

"Can Econometric Policy Evaluations Be Salvaged? - Reply.” Journal of Monetary Economics, Supplementary Series, 1976b, 1(2), p. 62.

McCallum, Bennett T. "Analysis of the Monetary Transmission Mechanism: Methodological Issues.” Working Paper 7395, National Bureau of Economic Research, 1999.

Meulendyke, Ann-Marie. U.S. Monetary Policy and Financial Markets. New York: Federal Reserve Bank of New York, 1989.

Morgan, Mary S. The History of Econometric Ideas. Cambridge: Cambridge University Press, 1990.

Muth, John F. "Rational Expectations and the Theory of Price Movements." Econometrica, 1961, 29(3), pp. 315-35.

Nelson, Charles R. and Plosser, Charles I. "Trends and Random Walks in Macroeconomic Time Series: Some Evidence and Implications." Journal of Monetary Economics, September 1982, 10(2), pp. 139-62.

Phelps, Edmund S. and Taylor, John B. "Stabilizing Powers of Monetary Policy Under Rational Expectations.” Journal of Political Economy, February 1977, 85(1), pp. 163-90.

Rotemberg, Julio J. "Sticky Prices in the United States." Journal of Political Economy, December 1982, 90(6), pp. 1187-211.

"Prices, Output, and Hours: An Empirical Analysis Based on a Sticky Price Model." Journal of Monetary Economics, June 1996, 37(3), pp. 505-33. 
and Woodford, Michael. "An Optimization Based Econometric Framework for the Evaluation of Monetary Policy." NBER Macroeconomics Annual, 1997. Cambridge, MA: MIT Press, 1997.

and _. "Interest Rate Rules in an

Estimated Sticky Price Model.” Working Paper 6618, National Bureau of Economic Research, 1999.

Sargent, Thomas J. and Wallace, Neil. "Rational' Expectations, the Optimal Monetary Instrument, and the Optimal Money Supply Rule.” Journal of Political Economy, April 1975, 83(2), pp. 241-54.

and "Rational Expectations and the Theory of Economic Policy." Journal of Monetary Economics, April 1976, 2(2), pp. 169-83.

Sims, Christopher A. "Macroeconomics and Reality." Econometrica, January 1980, 48(1), pp. 1-48.

"Policy Analysis with Econometric Models." Brookings Papers on Economic Activity, 1982, (1), pp. 107-152.

"Are Forecasting Models Usable for Policy

Analysis?" Federal Reserve Bank of Minneapolis Quarterly Review, Winter 1986, 10(1), pp. 2-16.
"Interpreting the Macroeconomic Time Series Facts: The Effects of Monetary Policy." European Economic Review, June 1992, 36(5), pp. 975-1000.

"The Role of Interest Rate Policy in the Generation and Propagation of Business Cycles: What Has Changed Since the "30s?" in Jeffrey C. Fuhrer and Scott Schuh, eds., Beyond Shocks: What Causes Business Cycles. Federal Reserve Bank of Boston Conference Series, No. 42, 1999, pp. 121-60.

and Zha, Tao A. "Does Monetary Policy Generate Recessions?” Working Paper 98-12, Federal Reserve Bank of Atlanta, 1998.

Strongin, Steven. "The Identification of Monetary Policy Disturbances: Explaining the Liquidity Puzzle." Journal of Monetary Economics, June 1995, 35(3), pp. 463-97.

Taylor, John B. "Staggered Wage Setting in a Macro Model." American Economic Review, May 1979, 69(2), pp. 108-13.

"The Monetary Transmission Mechanism: An Empirical Framework.” Journal of Economic Perspectives, Fall 1995, 9(4), pp. 11-26.

Wold, Hermann. "A Generalization of Causal Chain Models.” Econometrica, 1960, 28(2), pp. 443-63. 
REVIEW

138 JuLY/AUgust 2001 